\title{
Soft Tissue Complications and Timing of Surgery in Patients with a Tongue-type Displaced Intra-Articular Calcaneal Fracture; An International Retrospective Cohort Study.
}

\author{
De Boer A.S., Van Lieshout E.M.M., Van 't Land F., Misselyn D., Schepers T. \\ Den Hartog D., Verhofstad M.H.J.
}

\begin{abstract}
Introduction: Tongue-type displaced intra-articular calcaneal fractures (DIACF) are associated with a specific pattern of fracture displacement in contrast to joint depression fractures. This may result in tension of soft tissue in the posterior part of the heel. Tensioninduced ischemia can result in skin necrosis. The objectives of this study were to investigate whether patients with tongue-type calcaneal fractures exert a higher risk of complications, especially of the posterior soft tissues, than joint depression type fractures. Also, late interventions (e.g., antibiotics, debridements, and amputations) and the effect of timing of surgery on the complication rate was assessed.
\end{abstract}

Methods: In this international retrospective cohort study, data of adult patients with a DIACF in the period January 1, 2005 to December 31, 2015 were extracted from patients' medical files. Descriptive, univariate, and multivariable analyses were performed in SPSS.

Results: A total of 560 patients with 632 DIACF were included (295 tongue-type and 337 non-tongue-type fractures). At hospital presentation, $20.3 \%$ of the patients with a tongue-type fracture had compromised posterior soft tissue versus $12.8 \%$ with non-tongue-type fractures $(p=0.032)$. However, corrected for potential confounders the risk was no longer statistically significant (OR 1.497; 95\% Cl 0.831-2.696). Patients with a TT-DIACF had a 1.2 to 3.4-fold higher rate of any local wound complication (deep infections, and full thickness lesions, $\mathrm{p}<0.03$ ). In addition they had 2.0 to 8.0 -fold more intravenous antibiotics, debridements, soft tissue coverage procedures and amputations $(p<0.03)$. Patients who underwent surgery within two days after trauma had a higher risk to develop any complication, in particular superficial infections, when compared to surgery between 3-7 days, but no significant difference between 3-7 and $\geq 8$ days could be demonstrated.

Conclusion: Despite the fact that patients with a tongue-type fracture developed posterior skin and soft tissue compromise nearly twice as often, this difference disappeared after correction for confounders. The overall complication risk was increased in patients with tongue-type calcaneal fractures as compared to patients with a non-tongue-type fracture. Postponing surgery (3-7 days or $\geq 8$ days) in patients without severe (soft tissue) injuries, did not affect outcome. 


\section{INTRODUCTION}

According to Essex-Lopresti displaced intra-articular calcaneal fractures (DIACFs) can be divided, into either tongue-type or joint depression patterns (1). In a tongue-type DIACF, the fracture line disperses longitudinally from the articular surface and exits posteriorly through the calcaneal tuberosity. Hereby, the posterior tuberosity fragment is displaced superiorly and dorsally due to traction of the Achilles tendon and plantar fascia. This specific pattern of fracture displacement easily results in significant pressure on and tension to the skin covering the posterior part of the calcaneus. Too much or prolonged tension may aggravate trauma-induced soft tissue injury, due to additional soft tissue ischemia, and finally necrosis, and thus converting a closed fracture into an open one (Figure 1). Posterior skin compromise is described to occur in $21 \%$ of the patients with tongue-type calcaneal fractures (2).
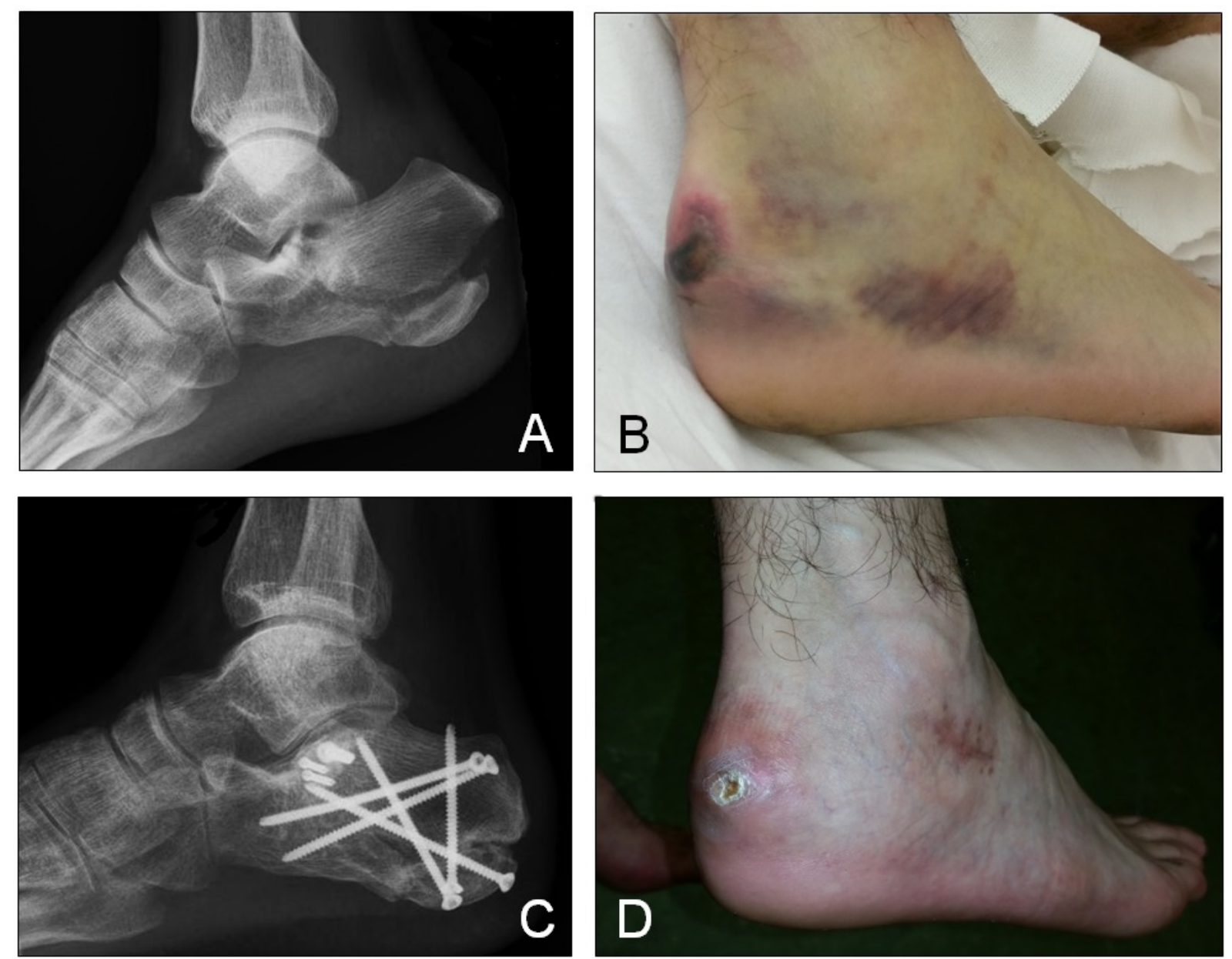

Figure 1. A. Lateral radiograph of a tongue-type DIACF at first hospital presentation, with severe displacement of the posterior tuberosity of the calcaneus. B. Presence and impending posterior soft tissue compromise (e.g., hematoma, blisters, and necrosis) due to the specific fracture displacement resulting in high tension on the skin. C. Status after Open Reduction and Internal Fixation (ORIF), 5 months after trauma. D. Wound healing after ORIF via Sinus Tarsi Approach.

Displaced intra-articular calcaneal fractures are often managed operatively (3). Postoperative wound infections occur frequently, often resulting in delayed wound healing and prolonged length of hospital stay, and sometimes in permanent iatrogenic disability $(4,5)$. In order to decrease the number of wound complications, it was thought that patients would benefit from delayed operative fixation of calcaneal fractures (6). However, failure to detect ongoing soft 
tissue deterioration during the (pre-operative) period may also lead to additional soft tissue morbidity $(1,5)$. It is the question whether a delayed surgical procedure is suitable for all calcaneal fractures.

It is hypothesized that delayed surgery of tongue-type DIACFs turns reversible skin ischemia (i.e., compromised skin perfusion due to the specific fracture displacement) into irreversible skin necrosis $(2,7)$. Tongue-type DIACFs might even be considered as a surgical urgency. To date, little has been reported on posterior soft tissue complications associated with tongue-type calcaneal fractures.

The primary aim, of this study was to compare the rate of posterior soft tissue compromise in adult patients with a tongue-type versus non-tongue-type DIACF. Secondary aims were 1) to compare the rate of other complications; 2) to compare the rate of late interventions; and 3) to examine the effect of timing of surgery on the complication rate.

\section{METHODS}

\section{Study design}

In this international, retrospective cohort study patients were identified from hospital records based upon their ICD-10 (International Coding of Diseases, $10^{\text {th }}$ revision) code S92.0, Diagnosis Related Group (DRG; in Dutch, DBC) code 236, or hospital specific surgical intervention codes. Data were extracted from the patient's medical files in the three participating hospitals.

Adult patients aged 18 years or older who were treated for a unilateral or bilateral DIACF (Essex-Lopresti tongue-type or joint depression type and Sanders type II-IV) between January 1, 2005 and December 31, 2015 were eligible for inclusion if a clinical follow-up of at least three months was documented. Patients suffering from local skin conditions that were not related to the fracture itself, but could influence outcome (e.g., burn or chemical wounds or pre-existing skin conditions in the affected foot region for example resulting from diabetes mellitus or venous insufficiency) and patients with a pathological calcaneal fracture were excluded.

\section{Data collection}

Patient characteristics (i.e., gender, age at trauma, ASA grade, Body Mass Index (BMI), comorbidities, and medication use), injury characteristics (i.e., date of trauma, affected side, trauma mechanism, fracture classifications $(1,8)$, soft tissue compromise, injury classifications (9), and radiographic fracture displacement measurements $(2,10)$ ), treatment characteristics (i.e., admission duration, method of swelling reduction, treatment type: Open Reduction and Internal Fixation (ORIF), Closed Reduction and Internal Fixation (CRIF), primary arthrodesis or non-operative treatment (i.e., plaster cast, a pressure bandage or PTB-Brace), initial soft tissue coverage), complications, and late interventions were obtained from the electronic patient's medical files.

Compromise was defined as the lack of sufficient blood supply for soft tissue to remain viable. Compromise is defined as a reversible condition, but could potentially result in more severe (e.g., infection), or irreversible conditions (e.g., necrosis). Soft tissue compromise is limited to the posterior part of the foot. Compromise at the anterior, lateral, and medial side were not registered as compromise, nor was compromise caused by external trauma. In this study the following conditions are registered as compromise, when occurred within three weeks post trauma (until the start of initial operative intervention, for patients treated operatively): hematoma, contusion, blisters, threatened skin (i.e., pallor or collateral blanchable redness of the skin), ischemia, partial thickness lesion (i.e., loss of integrity of the skin and subcutaneous tissue as result of prolonged ischemia), and full thickness lesion (i.e. communicating with periosteum, open fracture).

The following post-operative complications, although not all causally related to the operation, were collected: abrasion, hematoma, swelling, blisters, pallor, partial or full 
thickness lesion, necrosis, superficial infection (i.e., non-operative treatment, no admission, possibly oral antibiotics), deep infection (i.e., surgical intervention, admission, possibly intravenous antibiotics), compartment syndrome, implant failure, secondary dislocation, malalignment, non-union, sural nerve injury, tendon injury, paresthesia, persistent pain, or arthritis.

Fracture displacement was determined as described by Gardner et al. (2). The posterior facet (PF) angle was used to determine the plantar rotation of the PF of the calcaneus relative to the talus and was the primary radiographic measurement of fracture displacement. This was measured as the angle between the PF articular surface on the fracture fragment and the PF articular surface of the talus on the lateral radiograph (Figure 2). In addition, the research physician measured Böhler's angles.

In patients with bilateral fractures, the injury of the right foot was leading for stratification into either the tongue-type or the non-tongue-type group. Patients who had additional injuries were described as 'polytrauma'.
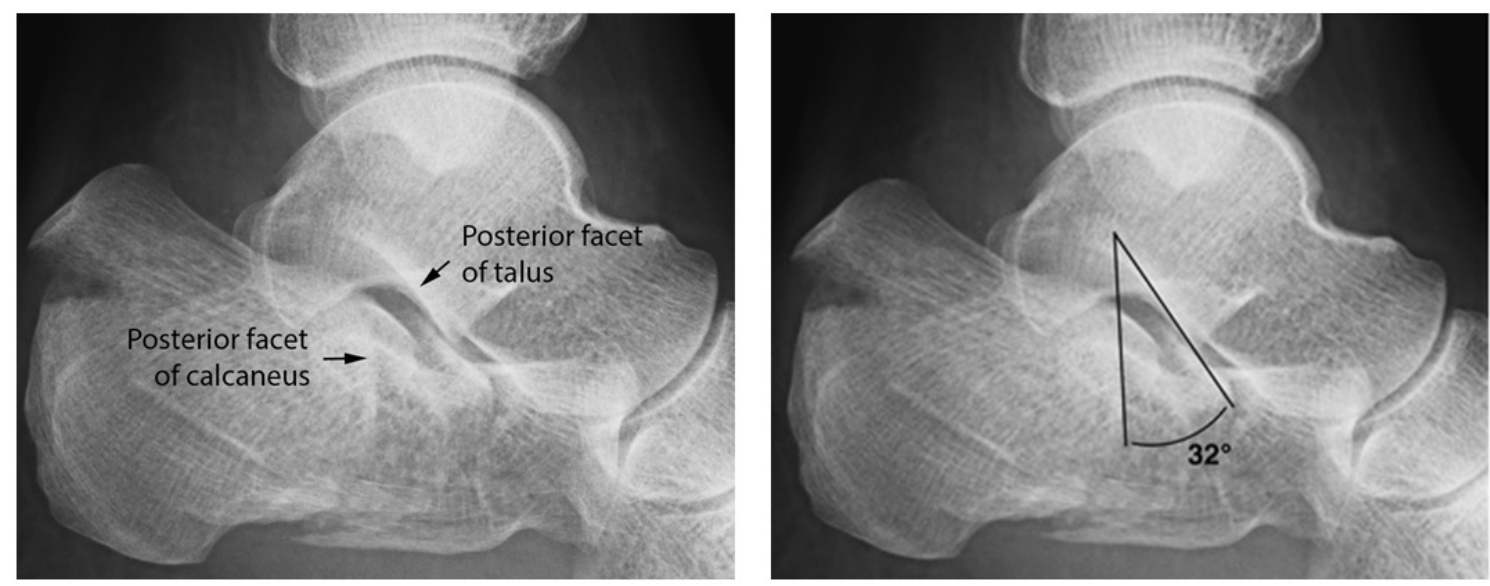

Figure 2. Fracture displacement according to Gardner et al. (2)

\section{Statistical analysis}

Data were analyzed using the Statistical Package for the Social Sciences (SPSS) version 21.0 (SPSS, Chicago, III., USA). The Youden index was analyzed using MedCalc version 14.10.2 (MedCalc Software, Ostend, Belgium). Normality of continuous data were tested with the Shapiro-Wilk test, and homogeneity of variances was tested using the Levene's test. A pvalue $<0.05$ was taken as threshold of statistical significance in all statistical tests, and all tests were two-sided. Missing values were not imputed.

Descriptive analysis was performed in order to report patient characteristics, injuryrelated variables and treatment-related variables per group. Differences between groups will be tested using Student's T-test or Mann-Whitney U-test (parametric and non-parametric continuous data, respectively) or a Chi-squared or Fisher's exact test (categorical data).

Univariate analysis of the rate of posterior soft tissue compromise was done using a Chi-squared test. Multivariable analysis was done as secondary analysis. Treatment and variables that may potentially confound the association between fracture type and soft tissue compromise were included in this model as covariate. Covariates were selected based upon literature data, by eyeballing the descriptive statistics and the covariates with a $p<0.200$ in the univariate analysis (Supplemental Tables 2-12). The beta values were reported as odd's ratio (OR) with 95\% confidence interval and p-value.

\section{RESULTS}


In total 735 patients were identified. After applying the inclusion criteria (23 patients were younger than 18 years, 104 patients did not have a DIACF, and 43 patients had a follow up less than three months), 565 patients were eligible for inclusion. Five patients were excluded; one patient had a pre-existent local skin condition that was not related to the fracture, two patients had a primary amputation, and two patients had an unknown Essex-Lopresti classification). This resulted in 560 included patients with 632 fractures (72 bilateral fractures). Of the patients with bilateral fractures, eighteen patients had a tongue-type fracture on the right side and a non-tongue-type fracture on the left side and were analyzed in the tongue-type group. Eleven patients had a non-tongue-type fracture on the right foot and a tongue-type on the left and were therefore analyzed in the non-tongue-type group. Fractures were classified according to the Essex-Lopresti classification in 295 (46.7\%) tongue-type calcaneal fractures and 337 (53.3\%) non-tongue-type fractures (i.e., jointdepression type or severely comminuted calcaneal fractures).

\section{Posterior soft tissue compromise}

The mean age of the patients in the tongue-type group was significantly lower than those in the non-tongue-type group (42 versus 46 years, $p=0.006$ ) (Supplemental Table 1 ). Other covariates such as gender, BMI, ASA scores, smoking status, alcohol consumption, comorbidities (except psychiatric), and medication usage did not differ significantly between patients with a tongue-type fracture and patients with a non-tongue-type fracture.

Significantly more patients had a psychiatric disorder in the tongue-type fracture group (18.6\% versus $11.6 \%, p=0.027)$. In the tongue-type group $247(83.7 \%)$ patients were treated operatively compared with 285 (84.6\%) patients in the non-tongue-type group $(p=$ 0.827 ). Significantly more polytrauma patients were observed in the tongue-type group (47.6\% versus $38.9 \%, p=0.040)$. A significantly larger amount of patient had contralateral lower extremity injuries $(18.6 \%$ versus $11.7 \%, p=0.031)$, pelvic injuries $(13.8 \%$ versus $8.1 \%$, $p=0.039)$ and spine injuries $(20.9 \%$ versus $12.1 \%, p=0.005)$ in the tongue-type group.

Posterior soft tissue compromise at hospital presentation was documented in 37 (20.3\%) of 182 tongue-type fractures, versus 26 (12.8\%) of the 203 non-tongue-type fractures $(p=0.032)$. A tongue-type fracture appeared to be a risk factor for developing posterior soft tissue compromise as compared to non-tongue-type fractures (OR 1.715; 95\% $\mathrm{Cl}$ 1.012-2.909; Table 1), but after correction for confounders this was no longer significant (OR 1.497; 95\% Cl 0.831-2.696). In the supplemental tables 1-12 the various covariates used in the multivariable analysis are shown.

Patients with a tongue-type fracture who developed compromised soft tissue posterior on the heel had a median fracture displacement (according to Gardner et al. (2)) of $22.5^{\circ}$ (SD 14.7) whereas patients who did not develop this compromise had a median displacement of $19.8^{\circ}$ (SD 14.8). This difference was not significant $(p=0.288)$. Also, no significant differences were found for other complications (i.e., superficial and deep infections, full thickness lesion, necrosis and non-unions), it only differed for partial thickness lesions.

Table 1: Posterior soft tissue compromise and complications in tongue-type versus non-tongue-type DIACFs

\begin{tabular}{|c|c|c|c|c|}
\hline Variable & OR (95\% Cl) & P-value & OR $(95 \% \mathrm{Cl})$ & P-value \\
\hline & Crude & & Adjusted & \\
\hline Posterior soft tissue compromise ${ }^{\mathrm{A}}$ & 1.715 (1.012-2.909) & 0.045 & $1.497(0.831-2.696)$ & 0.179 \\
\hline \multicolumn{5}{|l|}{ Complications } \\
\hline Any complication ${ }^{\mathrm{B}}$ & $1.546(1.121-2.130)$ & 0.008 & $1.813(1.178-2.791)$ & 0.007 \\
\hline Infection C & $1.351(0.925-1.974)$ & 0.120 & $1.728(1.082-2.761)$ & 0.022 \\
\hline Superficial $^{\mathrm{D}}$ & $1.003(0.622-1.618)$ & 0.989 & $1.209(0.700-2.088)$ & 0.496 \\
\hline
\end{tabular}


Deep ${ }^{\mathrm{E}}$

Lesions

Full Thickness ${ }^{F}$
Partial Thickness
${ }^{\mathrm{G}}$

Necrosis ${ }^{\mathrm{H}}$

Non-union'
1.695 (1.074-2.673)

0.023

$1.619(0.948-2.767)$

0.078
3.585 (1.404-9.155)

0.008

1.208 (0.674-2.164)

1.777 (0.925-3.413)

$1.236(0.586-2.605)$

0.526

0.084

0.578
3.043 (1.063-8.714)

0.038

0.702 (0.329-1.498)

0.360

1.244 (0.590-2.621)

0.566

OR is shown for tongue-type fractures compared with non-tongue-type fractures.

Data are shown as Odds Ratio (OR) with (95\% Confidence Interval $(\mathrm{Cl}))$ and analyzed using a multivariable logistic regression model. Outcomes are corrected for all relevant covariates with $p<0.200$ after univariate analysis (shown in supplemental tables 2-12).

A. Corrected for Böhler's angle at trauma, smoking, psychiatric disorder.

B. Corrected for BMI, Delay to Emergency Department, Böhler's angle at trauma, Hospital length of stay, ASA class, smoking, open or closed fractures, soft tissue injury at trauma, Diabetes Mellitus, additional injury, operative or non-operative treatment.

c. Corrected for BMI, Böhler's angle at trauma, Hospital length of stay, smoking, open or closed fractures, operative or non-operative treatment.

D. Corrected for Age, BMI, smoking, open or closed fractures, comorbidities, medication, soft tissue injury at trauma, operative or non-operative treatment.

E. Corrected for Böhler's angle at trauma, Hospital length of stay, smoking, open or closed fractures, operative or non-operative treatment.

F. Corrected for Hospital length of stay, smoking, operative or non-operative treatment.

G. Corrected for Delay to Emergency Department, Böhler's angle at trauma, Hospital length of stay, smoking, trauma mechanism, unilateral or bilateral fractures, additional injury, operative or non- operative treatment.

H. Corrected for Hospital length of stay, ASA class, smoking, open or closed fractures, soft tissue injury at trauma, time to surgery, operative or non-operative treatment.

I. Corrected for BMI, Böhler's angle at trauma, Hospital length of stay, smoking, trauma mechanism, open or closed fractures, soft tissue injury at trauma, operative or nonoperative treatment.

\section{Complications and late interventions}

As secondary objectives the rate of other complications and late interventions in patients with a tongue-type versus non-tongue-type calcaneal fracture was examined. In total $59.2 \%$ of the patients developed a complication. In patients with a tongue-type fracture significantly higher rates of overall complications (64.7\% versus $54.3 \%, p=0.009)$, deep infections $(17.3 \%$ versus $11.0 \%, p=0.028)$, and full thickness lesions (6.1\% versus $1.8 \%, p=0.006)$ occurred.

The univariate OR for patients with a tongue-type versus patients with a non-tonguetype calcaneal fracture are shown in Figure 3. In the total study population, patients with a tongue-type fracture have an increased risk to develop any complication (OR 1.546; 95\% 1.121-2.130), posterior soft tissue compromise (OR 1.715; 95\% Cl 1.012-2.909), deep infections (OR 1.695; 95\% Cl 1.074-2.673), and full thickness lesions (OR 3.585; 95\% Cl 1.404-9.155) compared to patients with non-tongue-type fractures. The operatively treated patients with a tongue-type fracture had a higher risk to develop any complication (OR 1.709; 95\% Cl 1.198-2.438), deep infection (OR 1.795; 95\% Cl 1.108-2.907), and full thickness lesions (OR $3.221 ; 95 \% \mathrm{Cl} 1.240-8.364$ ) than operatively treated patients with a non-tonguetype fracture. No significant difference between fracture types were found in non-operated patients. A multivariable analysis (Table 1) showed a significant higher risk for patients with tongue-type fractures of developing any complication (OR 1.813; 95\% Cl 1.178-2.791) and 
full thickness lesions (OR 3.043; 95\% Cl 1.063-8.714), but no significant higher risk of deep infections (OR 1.619; 95\% Cl 0.948-2.767).

Although the total rate of late interventions did not differ between the two fracture groups, significantly more amputations $(2.4 \%$ versus $0.3 \%, p=0.028)$, more debridements $(14.9 \%$ versus $7.1 \%, p=0.002)$, more treatment with intravenous antibiotics $(15.3 \%$ versus $7.7 \%, p=0.003)$, and more soft tissue coverage procedures $(12.2 \%$ versus $5.3 \%, p=0.003)$ were performed in patients with a tongue-type fracture.

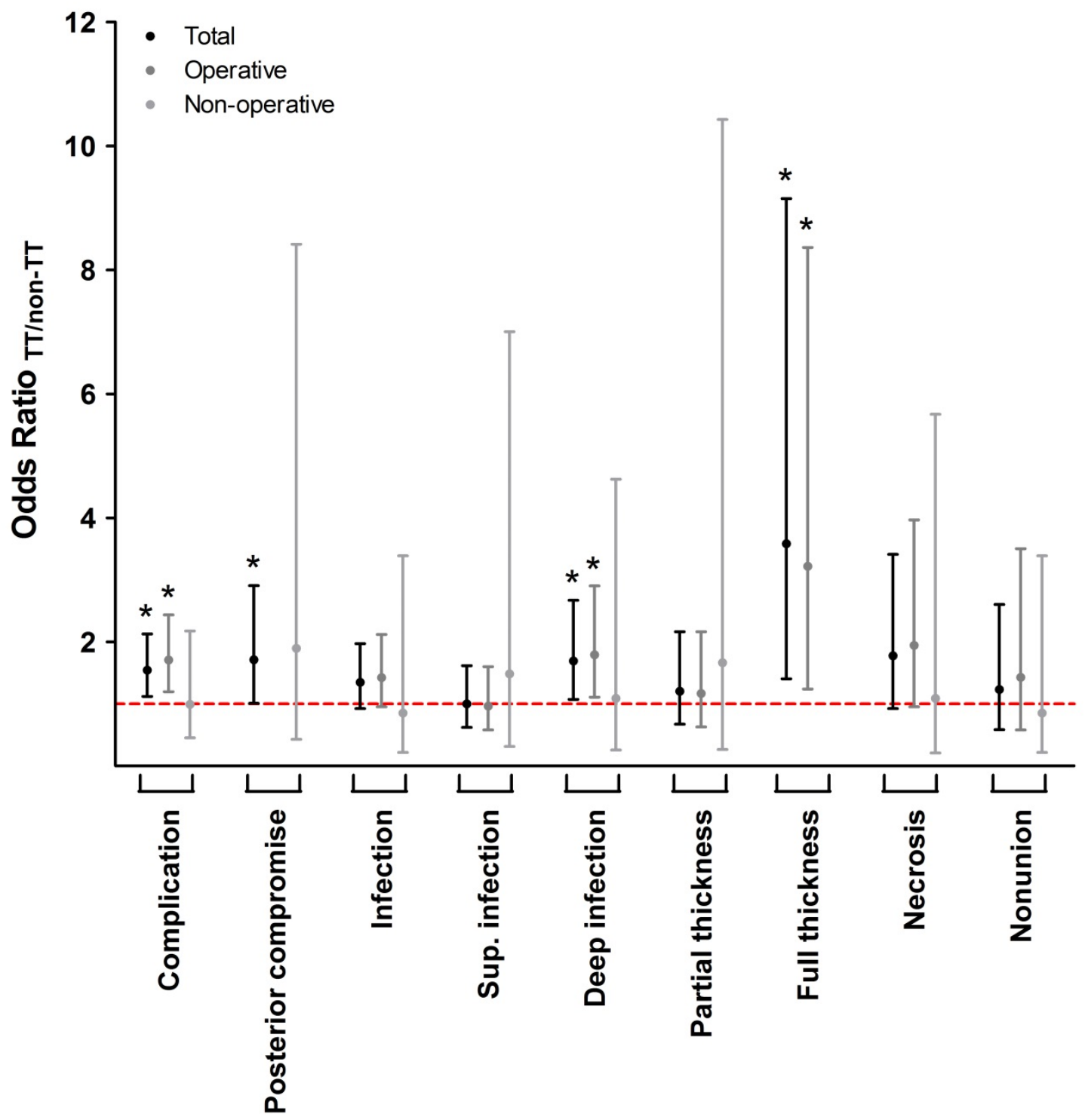

Figure 3. Odds Ratios (OR) for patients with tongue-type versus non-tongue-type calcaneal fractures. OR are shown for the total study population and for the operated and non-operated patients separately. OR are shown with a 95\% Confidence Interval. The dotted red line represents OR $=1$; *, significance. Not enough data was available in the operative group to analyse the risk for posterior compromise and in the non-operatively treated group for full thickness lesions.

Timing of surgery in patients with tongue-type calcaneal fractures

Next the relation between time to surgery and rate of (soft tissue) complications in patients with tongue-type DIACFs was investigated. Depending on the time to surgery, clinical relevance, and number of patients, patients with tongue-type DIACFs were stratified in four 
categories; operated between 0-2 days, 3-7 days, 8-14 days, and $\geq 15$ days. The surgical delay differed significantly in patients who developed infections $(p=0.009)$, deep infections $(p=0.034)$, full thickness lesions $(p=0.002)$, and non-union $(p=0.016)$, data is shown in Supplemental Tables 6,8,9, and 12. For these categories, the OR for the various outcomes are depicted in Figure 4. Operatively treated patients (OR surgery $\left._{\text {}}\right)$ had a higher risk to develop any complication (OR 2.312; 95\% Cl 1.236-4.324) or an infection (OR 4.197; 95\% Cl 1.44612.073 ) than non-operatively treated patients. Patients who underwent surgery within two days after trauma ( $\mathrm{t}=0-2 \mathrm{~d}$ ) had an higher risk to develop any complication (OR $3.548 ; 95 \% \mathrm{Cl}$ 1.176-10.711), and any infection (OR 2.920; 95\% Cl 1.095-7.787), in particular superficial infections (OR 4.144; 95\% Cl 1.230-13.763) than surgery between 3-7 days after trauma. The remaining outcomes (e.g., deep infection, partial and full thickness lesions, necrosis and non-union) did not statistically significant differ in the various time to surgery categories. No significant difference could be demonstrated between a surgical delay of 8 days or more (814 days or $\geq 15$ days) and 3-7 days.

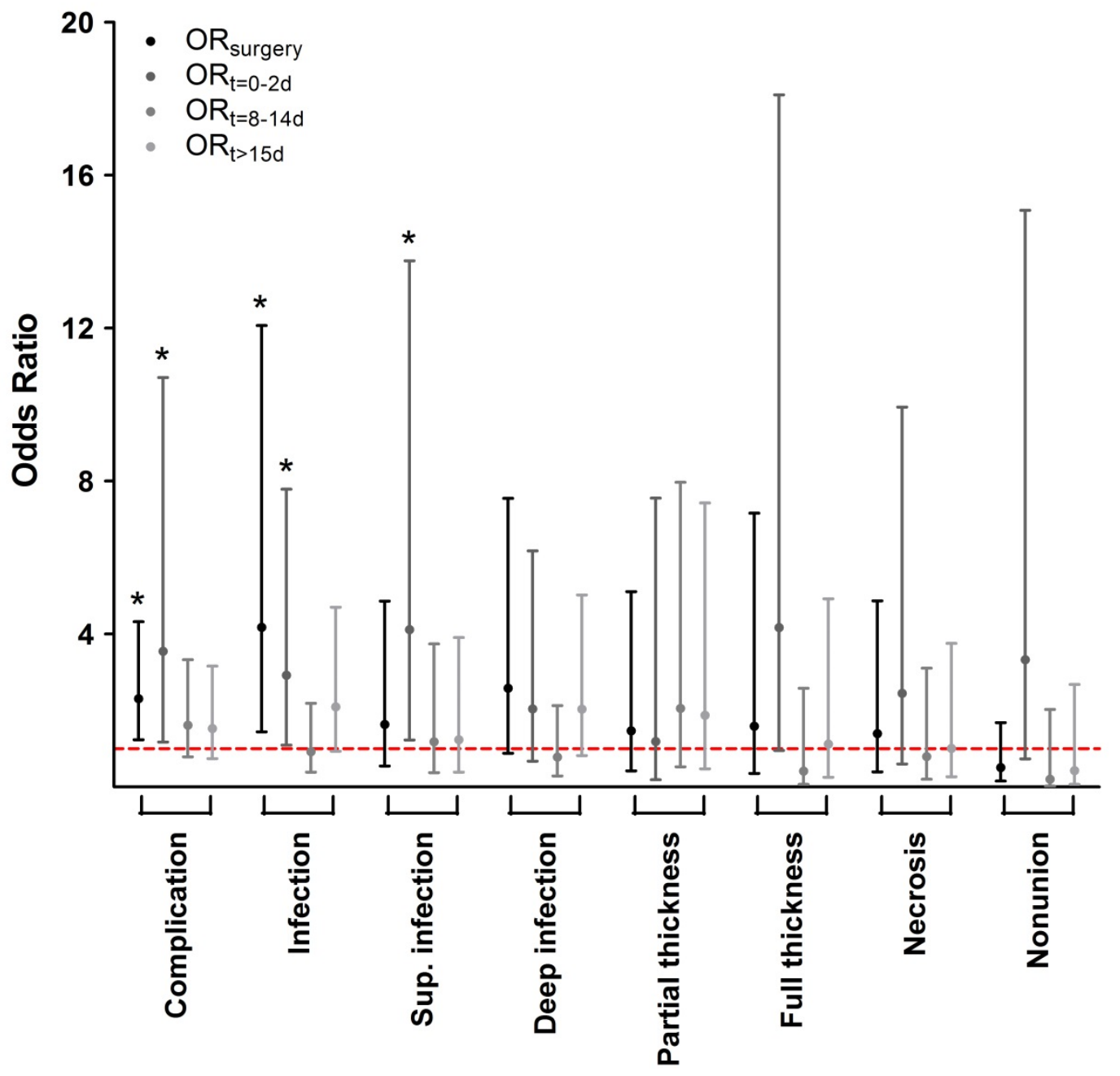

Figure 4. Odds Ratios (OR) for patients with a tongue-type DIACF. The 'time to surgery' categories ( $t=0-2, t=8-14$, and $t \geq 15$ days) are shown with 3-7 days as reference. OR are shown with a 95\% Confidence Interval. The dotted red line represents $O R=1$. Complication is the overall complication risk, and is subdivided in infection, partial and full thickness laesions, necrosis and nonunion. Infection in turn is subdivided in superficial and deep infections. $\mathrm{OR}_{\text {surgery, }}$ OR for operated patients; ${ }^{*}$, significance. 
In the subgroup of patients who underwent surgery at the day of trauma $(\mathrm{N}=20)$, the median fracture displacement was larger than in the total operated group $\left(33^{\circ}\right.$ versus $\left.18^{\circ}\right)$, Böhler's angle was more flattened $\left(-5.5^{\circ}\left(P_{50}-P_{75}-38.3-18.5\right)\right.$ versus $\left.8.0^{\circ}\left(P_{50}-P_{75}-4.0-17.0\right)\right)$ and the hospital length of stay was longer (23 days ( $\left.P_{50}-P_{75} 7-54\right)$ versus 7 days $\left(P_{50}-P_{75} 5-15\right)$ ). Furthermore, this subgroup had overall higher rates of adverse outcomes, in particular: comorbidities (62.5\% versus 39.8\%), High Energy Trauma (100\% versus $61.0 \%)$, additional injuries (72.2\% versus $41.2 \%)$, open fractures (55.0\% versus $4.4 \%)$, posterior compromise (25.0\% versus $9.9 \%)$, complications (85.0\% versus $61.3 \%)$, infections (35.0\% versus $23.9 \%)$, necrosis (20.0\% versus 5.8\%), and revision surgeries (80.0\% versus $51.5 \%)$. 


\section{DISCUSSION}

This study shows that posterior skin and soft tissue compromise at hospital presentation occurred in $20.3 \%$ of the patients with a tongue-type fracture versus $12.8 \%$ in patients with a non-tongue-type fracture. This result is in line with the findings of Gardner et al., who studied solely tongue-type calcaneal fractures and found posterior skin compromise in $20.9 \%$ (29 of total 139) of the tongue-type fractures at hospital presentation (2). Although posterior skin and soft tissue compromise occurred nearly twice as often in patients with a tongue-type fracture than in patients with a non-tongue-type fracture, this statistically significant difference disappeared after correction for confounders. Nevertheless, our findings and the current literature should alert clinicians about the potential pathomechanism of the specific fracture displacement in tongue-type calcaneal fractures $(2,7,11,12)$, to prevent soft tissue damage and the disastrous sequelae (13). Awareness of orthopaedic trauma surgeons about these risks should guide treatment decision (e.g., urgent fracture reduction and frequent monitoring of soft tissue conditions) to improve patient' outcomes and reduce complications.

The results of this study furthermore demonstrated an increased risk of developing overall complications, deep infections, and full thickness lesions in patients with a tonguetype DIACF compared with patients with a non-tongue-type fracture. To our knowledge, no other studies did investigate these specific outcomes in tongue-type fractures.

Patients with a tongue-type fracture were significantly more often polytrauma patients $(47.6 \%$ versus $38.9 \%$ ). This might be caused by the higher rate of high energy trauma (falls from height) in the tongue-type group. Whether this in turn is due to the significant higher rate of psychiatric disorders in this group not investigated in this study. Gardner et al. found 54\% additional injuries in patients with tongue-type fractures (2), which is in line with our findings.

In this study, fracture displacement did not significantly differ between patients with tonguetype fractures with and without posterior soft tissue compromise $\left(22.5^{\circ}\right.$ versus $19.8^{\circ}, \mathrm{p}=$ 0.288 ). This is in contrast with Gardner et al., who found that patients with tongue-type fractures and posterior skin compromise had a significantly greater fracture displacement $\left(36^{\circ}\right.$ versus $\left.25^{\circ}, p=0.007, O R=1.03\right)(2)$. One explanation for the discrepancy between Gardner et al. and this study could that, in this study, fracture displacement was also measured when the inferior tuberosity fragment was tilted. This can theoretically result in an undervaluation of the true fracture displacement according to Gardner's method. The fracture displacement did differ significantly between both fracture types, when it concerned partial thickness lesion. Finding a reliable model which could measure the relation between fracture displacement and skin tension would be of value for surgeons to adjust treatment strategy. In this model not only tension but also pressure due to dorsal displacement should be taken into account. Currently, such a risk model is not available. A recent study describes fracture displacement via the talo-tuber angle and talo-tuber distance (12), this might be a suggestion for future research.

One of the limitations associated with the retrospective design of this study is the data completeness in medical files. In daily practice, the post-traumatic skin condition is often not noted in medical files or noted without the exact location of a lesion. The incompleteness of medical files might explain why no evidence for a statistical significantly higher risk of posterior soft tissue compromise in tongue-type fractures could be demonstrated. Partly due to this limitation, the statistical power was insufficient to adequately answer the primary objective. The moderate file keeping and the related absence of evidence resulted in a need to double the number of patients required for a statistical power of $80 \%$. With the current number of 560 included patients (632 calcaneal fractures), the statistical power was $50.1 \%$. However, a prospective study with that number of patients would be challenging.

Patients treated operatively within two days seem to have a higher risk to develop any complication and (superficial) infections. Surgery within two days might not be urgent enough 
for specific patient as ischemia by then is often already developed into necrosis, hereafter complications are impermeable. Surgical urgencies might be defined as surgery performed within six hours. In this study, very few patients $(\mathrm{N}=20)$ underwent surgery at the day of trauma. Although this number of patients is too low to prove statistical significant differences, descriptive analysis was performed in order to investigate whether this subgroup differed from the remaining total study population. Data suggests that these patients (operated at the day of trauma) were selected for immediate surgery based on their overall worse clinical conditions or injury severity at hospital presentation. These patients are more likely to develop complications. Unfortunately, the question whether earlier surgery of (tongue-type) calcaneal fractures would reduce the rate of complications could not be answered based on the data provided in this study. In order to determine exactly when to operate these tonguetype fractures, prospective (randomized) studies are needed.

\section{CONCLUSION}

Despite the fact that patients with a tongue-type fracture developed posterior skin and soft tissue compromise nearly twice as often, this significant difference disappeared after correction for confounders. Patients with tongue-type calcaneal fractures had an increased risk of developing local soft tissue complications compared with patients with a non-tonguetype fracture. Although postponing surgery 3-7 or $\geq 8$ days does not affect outcome, this study could not prove that patients with tongue-type fractures require immediate surgery. 
SUPPLEMENTAL MATERIAL

Table 1: Demographic data for the study population, separated as tongue-type or non-tonguetype DIACF

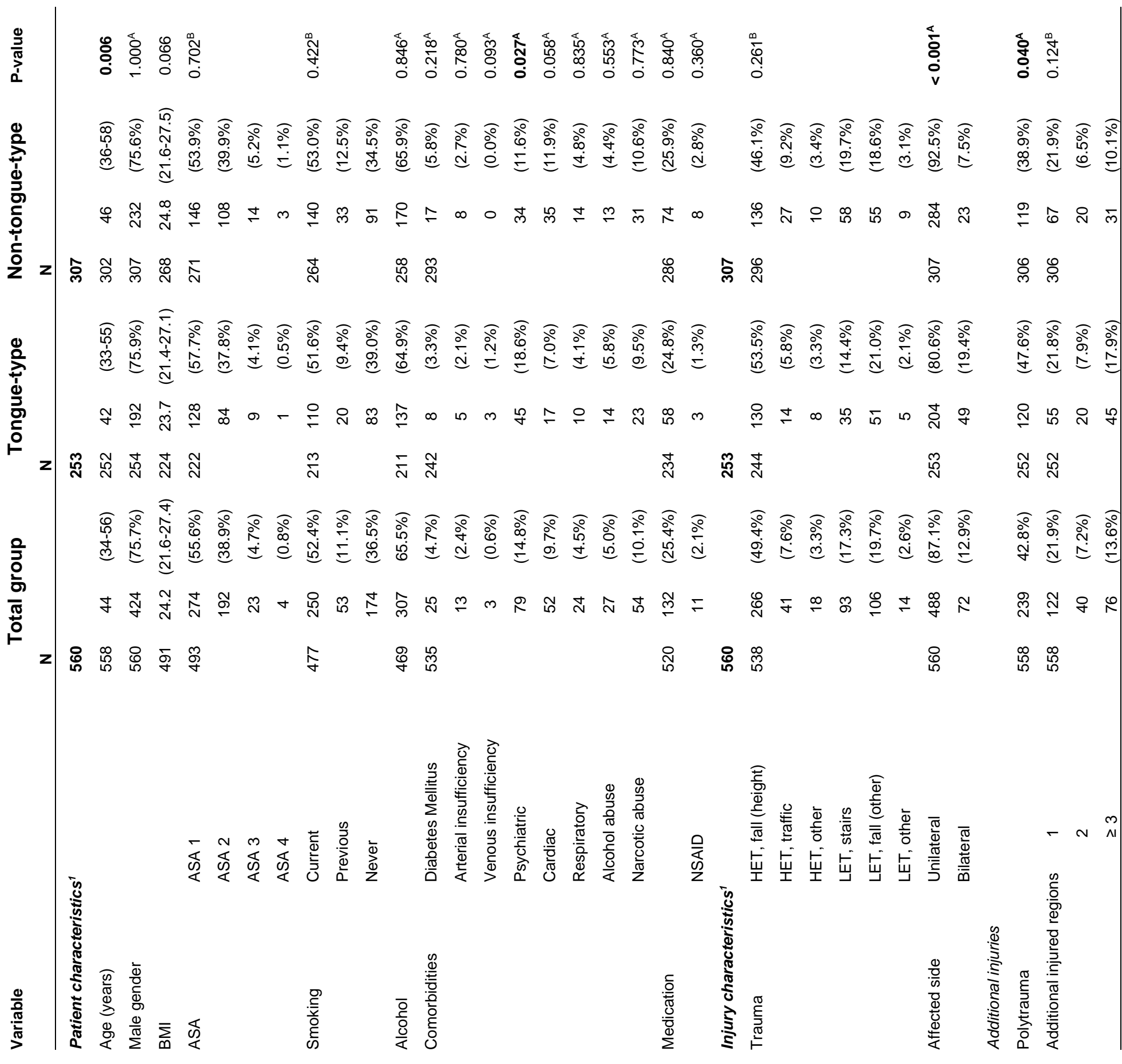

Continuous data are shown as median $\left(\mathrm{P}_{25}-\mathrm{P}_{75}\right)$ and analyzed using a Mann-Whitney U-test.

Categoric data are shown as N (\%) and analyzed using a AFisher's Exact test or ${ }^{\mathrm{B}}$ Chi-squared test, as applicable. Data are expressed per patient ${ }^{1}$ or per fracture ${ }^{2}$. 
Continuation Table 1: Demographic data for the study population, separated as tongue-type or non-tongue-type DIACF

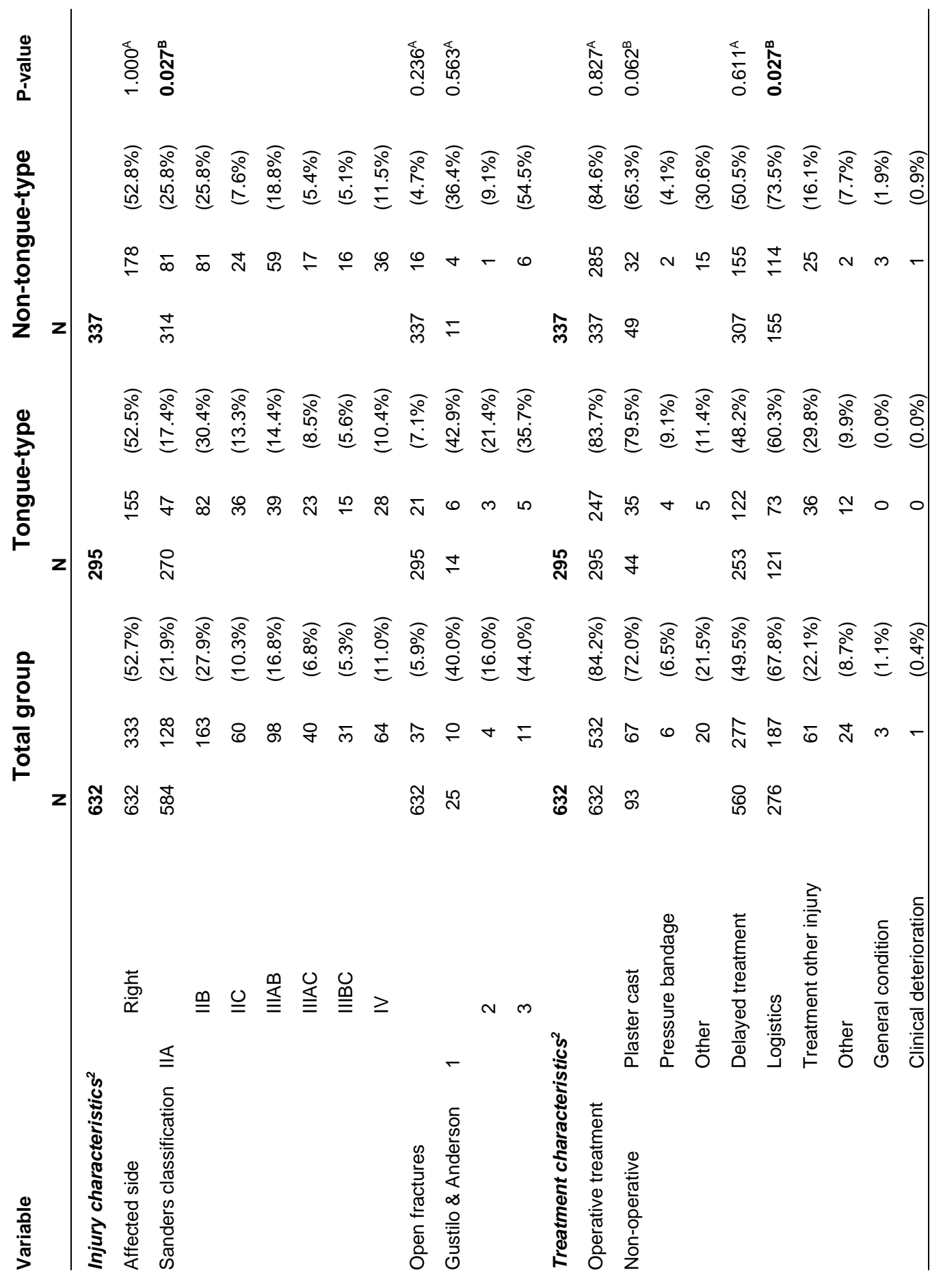


Table 2: Covariates for the total study population separated as TT versus non-TT

\begin{tabular}{|c|c|c|c|c|}
\hline \multicolumn{2}{|l|}{ Variable } & Non-tongue-type & Tongue-type & P-value \\
\hline \multicolumn{2}{|c|}{ Gender (Male) } & $232(75.6 \%)$ & $192(75.9 \%)$ & $1.000^{\mathrm{A}}$ \\
\hline \multicolumn{2}{|c|}{ Age (years) } & $45(36-57)$ & $42(32-54)$ & 0.006 \\
\hline \multicolumn{2}{|c|}{ BMI } & $24.8(21.6-27.5)$ & $23.7(21.4-27.1)$ & 0.066 \\
\hline \multirow[t]{4}{*}{ ASA } & I & $146(53.9 \%)$ & $128(57.7)$ & $0.702^{\mathrm{B}}$ \\
\hline & II & $108(39.9 \%)$ & $84(37.8 \%)$ & \\
\hline & III & $14(5.2 \%)$ & $9(4.1 \%)$ & \\
\hline & IV & $3(1.1 \%)$ & $1(0.5 \%)$ & \\
\hline \multirow[t]{3}{*}{ Smoking } & Current & $140(53.0 \%)$ & $110(51.6 \%)$ & $0.422^{\mathrm{B}}$ \\
\hline & Previous & $33(12.5 \%)$ & $20(9.4 \%)$ & \\
\hline & Never & $91(34.5 \%)$ & 83 (39.0\%) & \\
\hline \multicolumn{2}{|c|}{ Medication use } & $212(74.1 \%)$ & $176(75.2 \%)$ & 0.840 \\
\hline \multicolumn{2}{|c|}{ Trauma mechanism } & & & $0.129^{A}$ \\
\hline & LET & $127(39.1 \%)$ & $94(33.0 \%)$ & \\
\hline & HET & $198(60.9 \%)$ & $191(67.0 \%)$ & \\
\hline \multicolumn{2}{|c|}{ Time trauma to ED } & $0.0(0.0-0.0)$ & $0.0(0.0-0.0)$ & 0.260 \\
\hline \multicolumn{2}{|c|}{ Gardner's angle } & N.D. & $17.0(7.0-30.0)$ & N.D. \\
\hline \multicolumn{2}{|c|}{ Böhler's angle } & $9.0(-3.0-18.0)$ & $6.0(-6.3-17.0)$ & 0.022 \\
\hline \multirow[t]{3}{*}{ Side } & & & & $0.000^{\mathrm{A}}$ \\
\hline & Unilateral & $284(92.5 \%)$ & $204(80.6 \%)$ & \\
\hline & Bilateral & $23(7.5 \%)$ & 49 (19.4\%) & \\
\hline \multirow[t]{3}{*}{ Fracture } & & & & $0.236^{A}$ \\
\hline & Open & $321(95.3 \%)$ & $274(92.9 \%)$ & \\
\hline & Closed & $16(4.7 \%)$ & $21(7.1 \%)$ & \\
\hline \multicolumn{2}{|c|}{ Soft tissue compromise } & $86(25.5 \%)$ & $92(31.2 \%)$ & $0.132^{\mathrm{A}}$ \\
\hline & Posterior & $26(7.7 \%)$ & 37 (12.5\%) & $0.047^{A}$ \\
\hline \multicolumn{2}{|c|}{ Additional injury } & $119(38.9 \%)$ & $120(47.6 \%)$ & $0.040^{\mathrm{A}}$ \\
\hline \multicolumn{2}{|c|}{ Time trauma to surgery } & $11.0(5.0-17.0)$ & $10.0(6.0-16.0)$ & 0.363 \\
\hline \multicolumn{2}{|c|}{ Hospital length of stay } & $7.0(5.0-14.0)$ & $8.0(5.0-18.0)$ & 0.167 \\
\hline
\end{tabular}

A, Fisher's Exact Test; ${ }^{\text {, }}$ Pearson Chi-Square test. ED, Emergency Department. 
Table 3: Covariates for operated patients separated as TT versus non-TT

\begin{tabular}{|c|c|c|c|c|}
\hline \multicolumn{2}{|c|}{ Variable } & Non-tongue-type & Tongue-type & P-value \\
\hline \multicolumn{2}{|c|}{ Gender (Male) } & $200(75.5 \%)$ & $163(75.8 \%)$ & $1.000^{\mathrm{A}}$ \\
\hline \multicolumn{2}{|c|}{ Age (years) } & $45(36-57)$ & $41(32-53)$ & 0.004 \\
\hline \multicolumn{2}{|c|}{$\mathrm{BMI}$} & $24.8(21.8-27.4)$ & $23.7(21.4-26.6)$ & 0.068 \\
\hline \multirow[t]{4}{*}{ ASA } & 1 & $139(55.2 \%)$ & $124(61.1 \%)$ & $0.294^{\mathrm{B}}$ \\
\hline & II & $98(38.9 \%)$ & $70(34.5 \%)$ & \\
\hline & III & $12(4.8 \%)$ & $9(4.4 \%)$ & \\
\hline & IV & $3(1.2 \%)$ & $0(0.0 \%)$ & \\
\hline \multirow[t]{3}{*}{ Smoking } & Current & $125(52.7 \%)$ & $95(50.3 \%)$ & $0.751^{\mathrm{B}}$ \\
\hline & Previous & $25(10.5 \%)$ & $18(9.5 \%)$ & \\
\hline & Never & $87(69.7 \%)$ & $76(40.2 \%)$ & \\
\hline \multicolumn{2}{|c|}{ Medication use } & $60(23.8 \%)$ & $46(22.5 \%)$ & 0.824 \\
\hline \multicolumn{2}{|c|}{ Trauma mechanism } & & & $0.172^{\mathrm{A}}$ \\
\hline & LET & $112(40.3 \%)$ & $82(34.3 \%)$ & \\
\hline & HET & $166(59.7 \%)$ & $157(65.7 \%)$ & \\
\hline \multicolumn{2}{|c|}{ Time trauma to ED } & $0.0(0.0-0.0)$ & $0.0(0.0-0.0)$ & 0.210 \\
\hline \multicolumn{2}{|c|}{ Gardner's angle } & N.D. & $18.0(8.0-30.0)$ & N.D. \\
\hline \multicolumn{2}{|c|}{ Böhler's angle } & $8.0(-3-18.0)$ & $6.0(-8.0-15.0)$ & 0.025 \\
\hline \multicolumn{2}{|c|}{ Side } & & & $0.001^{\mathrm{A}}$ \\
\hline & Unilateral & $246(92.8 \%)$ & $178(82.8 \%)$ & \\
\hline & Bilateral & $19(7.2 \%)$ & $37(17.2 \%)$ & \\
\hline \multicolumn{3}{|c|}{ Fracture (Open/Closed) } & & $0.480^{\mathrm{A}}$ \\
\hline & Open & $16(5.6 \%)$ & $18(7.3 \%)$ & \\
\hline & Closed & $269(94.4 \%)$ & $229(92.7 \%)$ & \\
\hline Soft tissue & promise & $71(24.9 \%)$ & $82(33.2 \%)$ & 0.044 \\
\hline & Posterior & $23(8.1 \%)$ & $32(13.0 \%)$ & 0.086 \\
\hline Additional & & $102(38.5 \%)$ & $100(46.5 \%)$ & 0.078 \\
\hline Time trau & surgery & $11.0(5.0-17.0)$ & $10.0(6.0-16.0)$ & 0.363 \\
\hline Hospital It & of stay & $7.0(5.0-14.0)$ & $7.5(5.0-17.0)$ & 0.304 \\
\hline
\end{tabular}

A, Fisher's Exact Test; ${ }^{\text {, }}$ Pearson Chi-Square test. ED, Emergency Department. 
Table 4: Covariates for the study population with versus without posterior compromise

\begin{tabular}{|c|c|c|c|c|c|}
\hline \multicolumn{2}{|l|}{ Variable } & $\begin{array}{l}\text { No posterior } \\
\text { compromise }\end{array}$ & $\begin{array}{c}\text { Posterior } \\
\text { compromise }\end{array}$ & P-value & $\begin{array}{c}\text { OR }(95 \% \mathrm{Cl}) \\
\text { adjusted }\end{array}$ \\
\hline \multicolumn{2}{|c|}{ Gender (Male) } & $376(74.9 \%)$ & $48(82.8 \%)$ & $0.257^{A}$ & \\
\hline \multicolumn{2}{|c|}{ Age (years) } & $43(33-56)$ & $46(37-56)$ & 0.334 & \\
\hline \multicolumn{2}{|c|}{$\mathrm{BMI}$} & $24.5(21.5-27.4)$ & $23.6(21.6-26.9)$ & 0.803 & \\
\hline \multirow[t]{4}{*}{ ASA } & 1 & $244(55.7 \%)$ & $30(54.5 \%)$ & $0.259^{B}$ & \\
\hline & II & $168(38.4 \%)$ & $24(43.6 \%)$ & & \\
\hline & III & $23(5.3 \%)$ & $0(0.0 \%)$ & & \\
\hline & IV & $3(0.7 \%)$ & $1(1.8 \%)$ & & \\
\hline \multirow[t]{3}{*}{ Smoking } & Current & $224(52.2 \%)$ & 26 (54.2\%) & $0.874^{B}$ & $1.236(0.649-2.355)$ \\
\hline & Previous & $47(11.0 \%)$ & $6(12.5 \%)$ & & $1.497(0.550-4.076)$ \\
\hline & Never & $158(36.8 \%)$ & $16(33.3 \%)$ & & \\
\hline \multicolumn{2}{|c|}{ Comorbidities } & $278(57.8 \%)$ & $29(53.7 \%)$ & $0.565^{A}$ & \\
\hline & Diabetes Mellitus & $24(5.0 \%)$ & $1(1.9 \%)$ & $0.498^{A}$ & \\
\hline & Psychiatric & $68(14.1 \%)$ & $11(20.4 \%)$ & $0.226^{A}$ & \\
\hline \multicolumn{6}{|l|}{ disorder } \\
\hline \multicolumn{2}{|c|}{ Medication use } & 117 (25.1\%) & $15(28.3 \%)$ & $0.619^{A}$ & \\
\hline \multicolumn{2}{|c|}{ Trauma mechanism } & & & $0.212^{\mathrm{A}}$ & \\
\hline & LET & $194(35.4 \%)$ & 27 (43.5\%) & & \\
\hline & HET & $354(64.6 \%)$ & $35(56.5 \%)$ & & \\
\hline \multicolumn{2}{|c|}{ Time trauma to ED } & $0.0(0.0-0.0)$ & $0.0(0.0-0.0)$ & 0.962 & \\
\hline \multicolumn{2}{|c|}{ Gardner's angle } & $16.0(6.0-29.0)$ & $20.0(11.3-32.8)$ & 0.151 & \\
\hline \multicolumn{2}{|c|}{ Böhler's angle } & $8.0(-5.0-18.0)$ & $6.5(-6.0-12.5)$ & 0.132 & 0.997 (0.980-1.014) \\
\hline \multirow[t]{3}{*}{ Side } & & & & $1.000^{\mathrm{A}}$ & \\
\hline & Unilateral & 437 (87.1\%) & $51(87.9 \%)$ & & \\
\hline \multirow{2}{*}{\multicolumn{3}{|c|}{ Fracture (Open/Closed) }} & 7 (12.1\%) & & \\
\hline & & & & $0.402^{\mathrm{A}}$ & \\
\hline & Open & $32(5.6 \%)$ & $5(7.9 \%)$ & & \\
\hline & Closed & $537(94.4 \%)$ & 58 (92.1\%) & & \\
\hline \multicolumn{2}{|c|}{ Fracture type } & & & $0.047^{A}$ & $1.497(0.831-2.696)$ \\
\hline & Non-tongue-type & $311(54.7 \%)$ & $26(41.3 \%)$ & & \\
\hline & Tongue-type & $258(45.3 \%)$ & $37(58.7 \%)$ & & \\
\hline Soft tissu & promise & $115(20.2 \%)$ & $63(100.0 \%)$ & $0.000^{A}$ & \\
\hline Time trat & surgery & $11.0(6.0-17.0)$ & $8.0(4.0-13.0)$ & 0.008 & \\
\hline Hospital & of stay & $7.0(5.0-16.0)$ & $8.0(5.0-11.0)$ & 0.655 & \\
\hline
\end{tabular}

Univariate OR $(95 \% \mathrm{Cl})$ for tongue-type fractures: 1.715 (95\% Cl 1.012-2.909, p=0.045).

A, Fisher's Exact Test; ${ }^{B}$, Pearson Chi-Square test; OR, Odds Ratio. Significant p-values and OR are marked bold. The $95 \% \mathrm{Cl}$ spanning 1 means no significant difference. A univariate $p$-value $<0.200$ was chosen as threshold for including covariates (relevant for the outcome) in the multivariate analysis. In the multivariate analysis Gardner's angle was not included since the angle was only measured in tongue-type calcaneal fractures. 
Table 5: Covariates for the study population with versus without complications

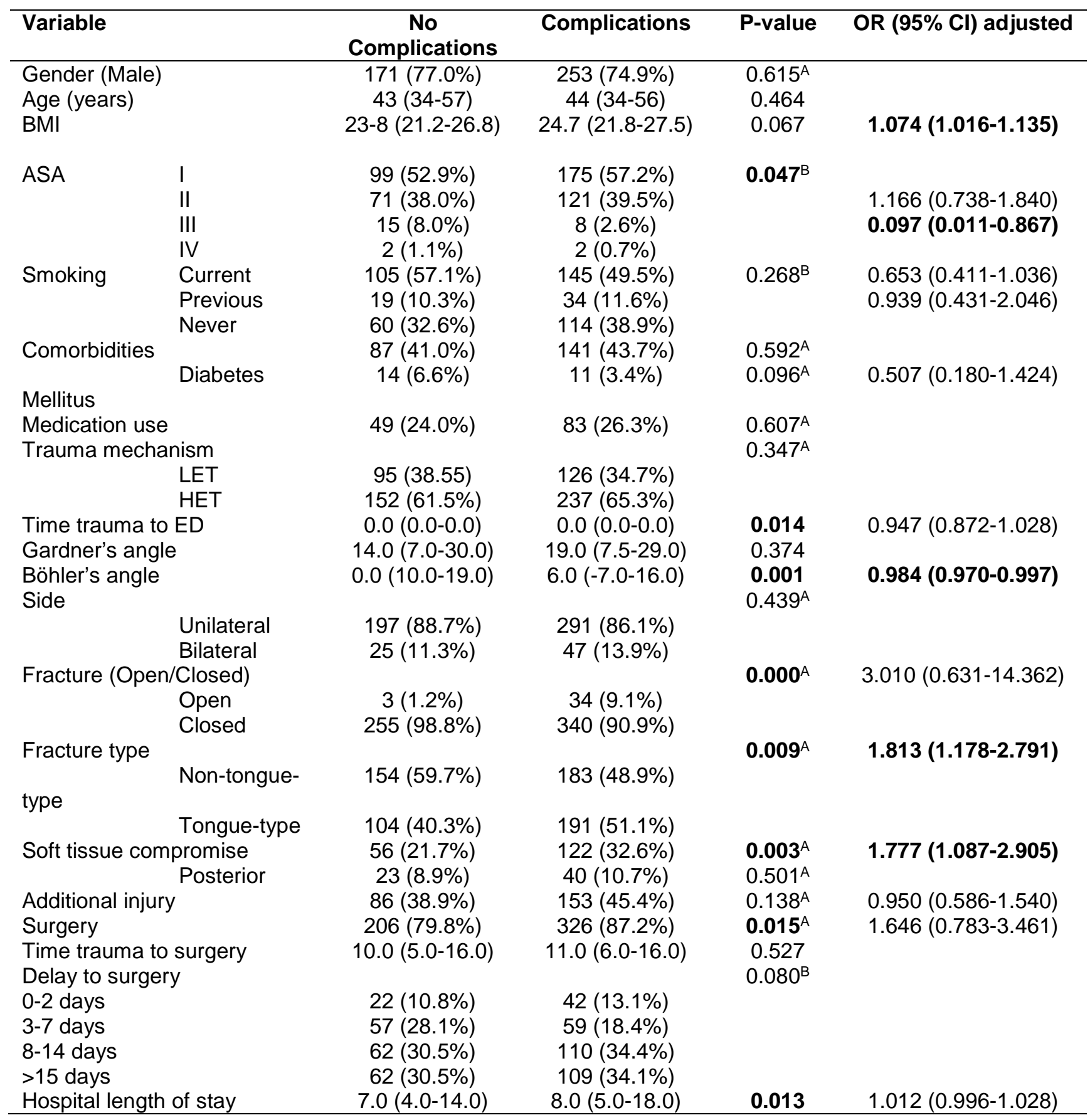

Univariate OR $(95 \% \mathrm{Cl})$ for tongue-type fractures: 1.546 (95\% Cl 1.121-2.130, p=0.008).

A, Fisher's Exact Test; ${ }^{B}$, Pearson Chi-Square test. 
Table 6: Covariates for the study population with versus without infections

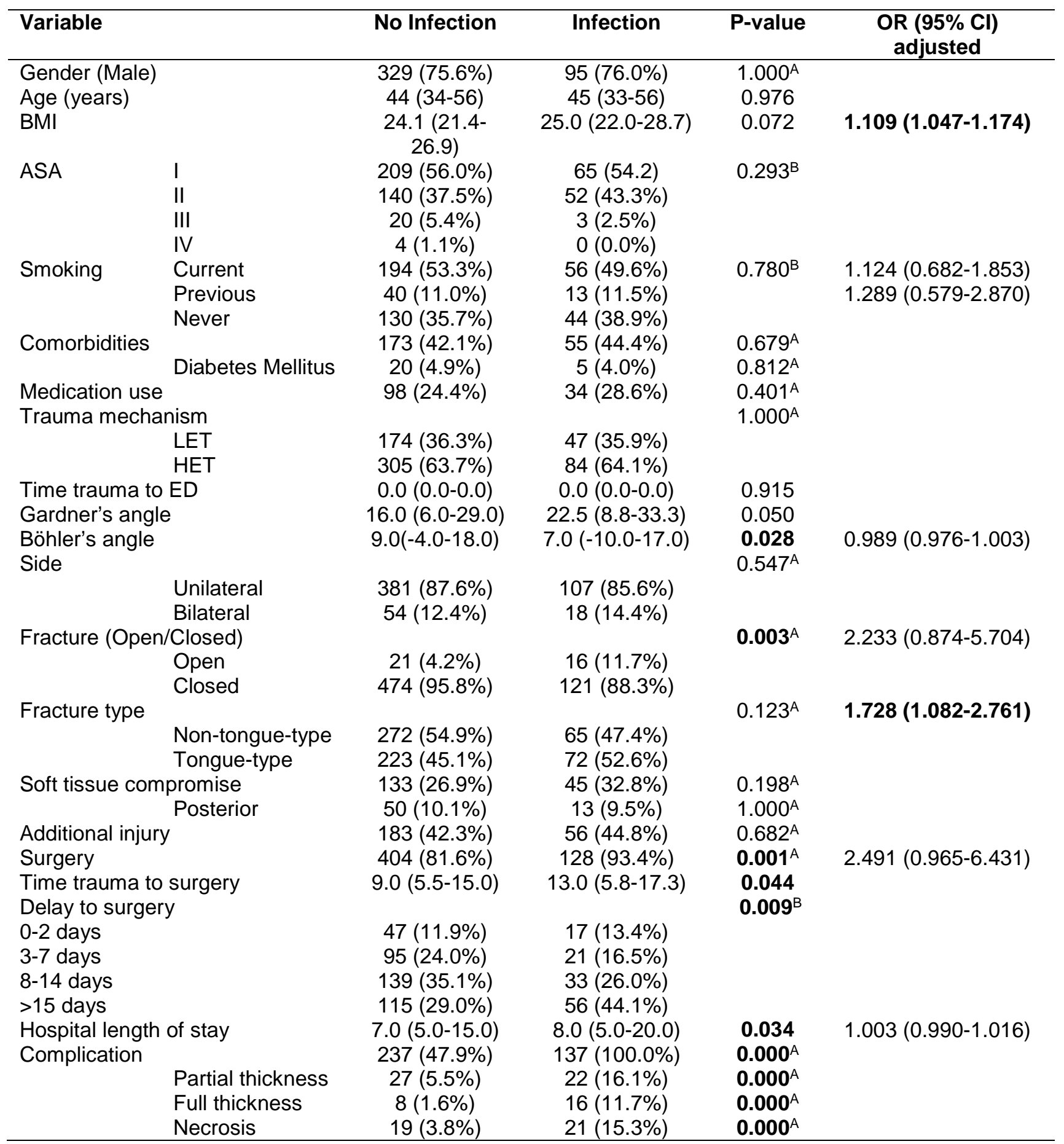

Univariate OR $(95 \% \mathrm{Cl})$ for tongue-type fractures: 1.351 (95\% Cl 0.925-1.974, $\mathrm{p}=0.120)$.

A, Fisher's Exact Test; ${ }^{B}$, Pearson Chi-Square test 
Table 7: Covariates for the study population with versus without superficial infections

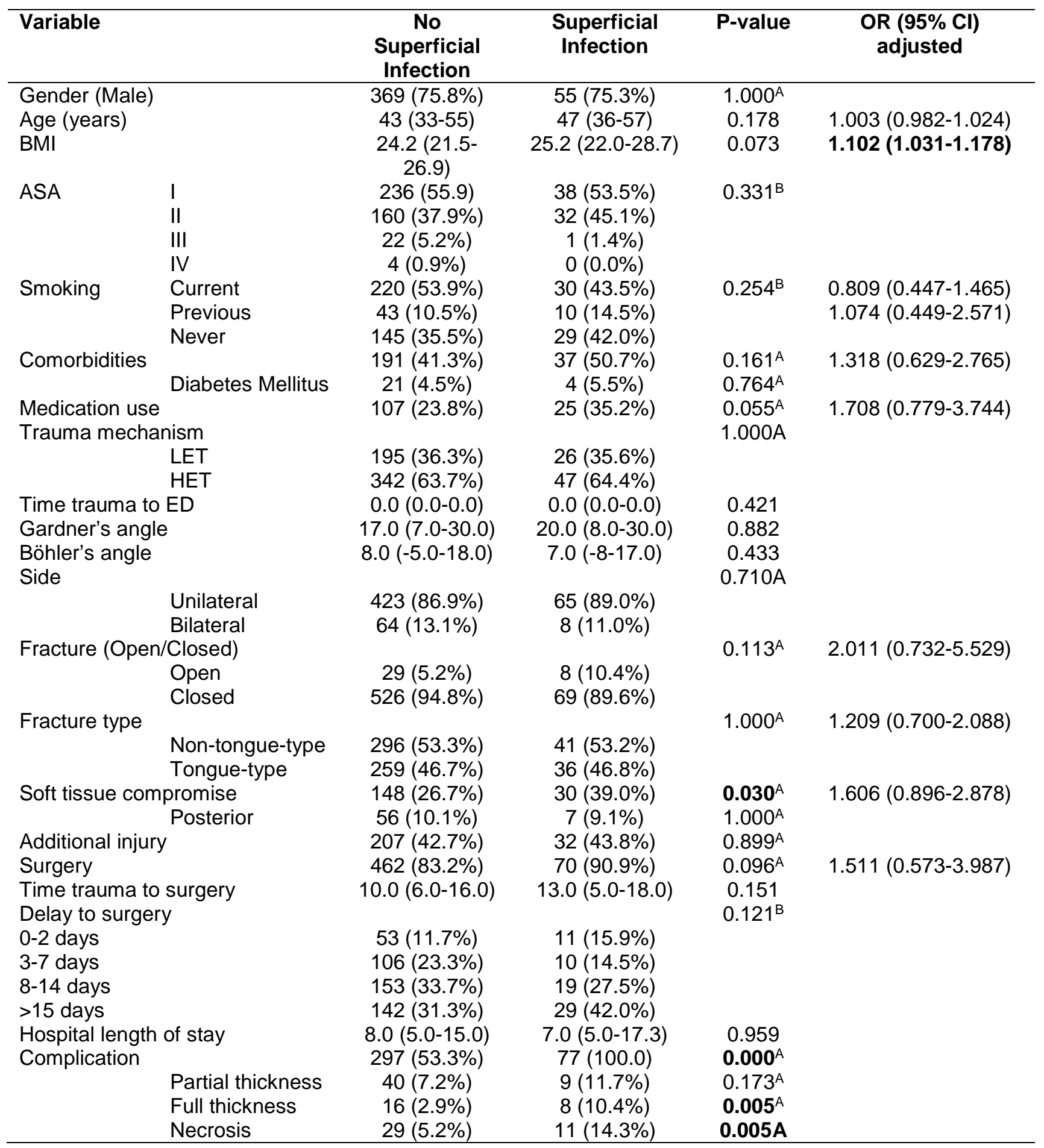

Univariate OR (95\% Cl) for tongue-type fractures: 1.003 (95\% Cl 0.622-1.618, $\mathrm{p}=0.989)$.

A, Fisher's Exact Test; ${ }^{\circ}$, Pearson Chi-Square test 
Table 8: Covariates for the study population with versus without deep infections

\begin{tabular}{|c|c|c|c|c|c|}
\hline \multicolumn{2}{|l|}{ Variable } & $\begin{array}{l}\text { No Deep } \\
\text { Infection }\end{array}$ & Deep Infection & P-value & $\begin{array}{c}\text { OR }(95 \% \mathrm{Cl}) \\
\text { adjusted }\end{array}$ \\
\hline \multicolumn{2}{|c|}{ Gender (Male) } & $367(76.0 \%)$ & $57(74.0 \%)$ & $0.775^{\mathrm{A}}$ & \\
\hline \multicolumn{2}{|c|}{ Age (years) } & $44(34-56)$ & $44(32-54)$ & 0.503 & \\
\hline \multicolumn{2}{|c|}{ BMI } & $\begin{array}{c}24.2(21.4- \\
27.0)\end{array}$ & $24.7(22.1-28.9)$ & 0.181 & \\
\hline \multirow[t]{4}{*}{ ASA } & 1 & $237(56.6 \%)$ & $37(50.0 \%)$ & $0.324^{\mathrm{B}}$ & \\
\hline & II & $157(37.5 \%)$ & $35(47.3 \%)$ & & \\
\hline & III & $21(5.0 \%)$ & $2(2.7 \%)$ & & \\
\hline & IV & $4(1.0 \%)$ & $0(0.0 \%)$ & & \\
\hline \multirow[t]{3}{*}{ Smoking } & Current & $211(51.3 \%)$ & $39(59.1 \%)$ & $0.499^{B}$ & $1.392(0.784-2.471)$ \\
\hline & Previous & $47(11.4 \%)$ & $6(9.1 \%)$ & & $0.996(0.350-2.838)$ \\
\hline & Never & $153(37.2 \%)$ & $21(31.8 \%)$ & & \\
\hline \multicolumn{2}{|c|}{ Comorbidities } & $197(42.9 \%)$ & $31(40.8 \%)$ & $0.803^{A}$ & \\
\hline & Diabetes Mellitus & $21(4.6 \%)$ & $4(5.3 \%)$ & $0.769^{A}$ & \\
\hline \multicolumn{2}{|c|}{ Medication use } & $113(25.2 \%)$ & $19(26.4 \%)$ & $0.884^{\mathrm{A}}$ & \\
\hline \multicolumn{2}{|c|}{ Trauma mechanism } & & & $0.715^{\mathrm{A}}$ & \\
\hline & LET & 189 (35.9\%) & $32(38.1 \%)$ & & \\
\hline & HET & $337(64.1 \%)$ & $52(61.9 \%)$ & & \\
\hline \multicolumn{2}{|c|}{ Time trauma to ED } & $0.0(0.0-0.0)$ & $0.0(0.0-0.0)$ & 0.283 & \\
\hline \multicolumn{2}{|c|}{ Gardner's angle } & $16.0(7.0-30.0)$ & $24.5(8.8-33.3)$ & 0.090 & \\
\hline \multicolumn{2}{|c|}{$\begin{array}{l}\text { Böhler's angle } \\
\text { Side }\end{array}$} & $9.0(-4-18.0)$ & $5.0(-14.0-15.5)$ & 0.023 & $0.993(0.978-1.008)$ \\
\hline \multicolumn{2}{|c|}{ Side } & & & $0.143^{\mathrm{A}}$ & \\
\hline & Unilateral & $425(88.0 \%)$ & $63(81.8 \%)$ & & \\
\hline & Bilateral & $58(12.0 \%)$ & $14(18.2 \%)$ & & \\
\hline \multicolumn{2}{|c|}{ Fracture (Open/Closed) } & & & $0.011^{A}$ & $2.504(1.001-6.262)$ \\
\hline & Open & $26(4.8 \%)$ & $11(12.5 \%)$ & & \\
\hline & Closed & $518(95.2 \%)$ & 77 (87.5\%) & & \\
\hline \multicolumn{2}{|c|}{ Fracture type } & & & $0.028^{A}$ & $1.619(0.948-2.767)$ \\
\hline & Non-tongue-type & $300(55.1 \%)$ & $37(42.0 \%)$ & & \\
\hline & Tongue-type & $244(44.9 \%)$ & $51(58.0 \%)$ & & \\
\hline \multicolumn{2}{|c|}{ Soft tissue compromise } & $150(27.6 \%)$ & $28(31.8 \%)$ & $0.444^{\mathrm{A}}$ & \\
\hline & Posterior & $52(9.6 \%)$ & $11(12.5 \%)$ & $0.441^{\mathrm{A}}$ & \\
\hline \multicolumn{2}{|c|}{ Additional injury } & $206(42.8 \%)$ & $33(42.9 \%)$ & $1.000^{\mathrm{A}}$ & \\
\hline \multicolumn{2}{|c|}{ Surgery } & $452(83.1 \%)$ & 80 (90.9\%) & $0.082^{\mathrm{A}}$ & $1.544(0.626-3.807)$ \\
\hline \multicolumn{2}{|c|}{ Time trauma to surgery } & $10.0(6.0-16.0)$ & $12.5(5.5-17.0)$ & 0.210 & \\
\hline \multicolumn{2}{|c|}{ Delay to surgery } & & & $0.034^{B}$ & \\
\hline \multicolumn{2}{|c|}{$\begin{array}{l}\text { Delay to surgery } \\
0-2 \text { days }\end{array}$} & $54(12.2 \%)$ & $10(12.5 \%)$ & & \\
\hline \multicolumn{2}{|l|}{ 3-7 days } & $102(23.0 \%)$ & $14(17.5 \%)$ & & \\
\hline \multicolumn{2}{|l|}{ 8-14 days } & $153(34.5 \%)$ & $19(23.8 \%)$ & & \\
\hline \multicolumn{2}{|c|}{$>15$ days } & $134(30.2 \%)$ & $37(46.2 \%)$ & & \\
\hline Hospital le & of stay & $7.0(5.0-15.0)$ & $9.5(6.0-21.0)$ & 0.006 & $1.010(0.997-1.024)$ \\
\hline Complica & & $286(52.6 \%)$ & $88(100.0 \%)$ & $0.000^{\mathrm{A}}$ & \\
\hline & Partial thickness & $31(5.7 \%)$ & $18(20.5 \%)$ & $0.000^{\mathrm{A}}$ & \\
\hline & Full thickness & $9(1.7 \%)$ & $15(17.0 \%)$ & $0.000^{A}$ & \\
\hline & Necrosis & $21(3.9 \%)$ & 19 (21.6\%) & $0.000^{A}$ & \\
\hline
\end{tabular}

Univariate OR $(95 \% \mathrm{Cl})$ for tongue-type fractures: $1.695(95 \% \mathrm{Cl} 1.074-\mathbf{2 . 6 7 3}, \mathbf{p}=\mathbf{0 . 0 2 3})$.

A, Fisher's Exact Test; ${ }^{\text {, }}$ Pearson Chi-Square test 
Table 9: Covariates for the study population with versus without full thickness lesion

\begin{tabular}{|c|c|c|c|c|c|}
\hline \multicolumn{2}{|l|}{ Variable } & $\begin{array}{c}\text { No Full } \\
\text { thickness lesion }\end{array}$ & $\begin{array}{c}\text { Full thickness } \\
\text { lesion }\end{array}$ & P-value & OR $(95 \% \mathrm{Cl})$ adjusted \\
\hline \multicolumn{2}{|c|}{ Gender (Male) } & $409(75.7 \%)$ & $15(75.0 \%)$ & $1.000^{\mathrm{A}}$ & \\
\hline \multicolumn{2}{|c|}{ Age (years) } & $44(34-56)$ & $43(31-54)$ & 0.440 & \\
\hline \multicolumn{2}{|c|}{ BMI } & $24.2(21.5-27.2)$ & $26(22-28)$ & 0.146 & \\
\hline \multirow[t]{4}{*}{ ASA } & I & 266 (56.2\%) & $8(40.0 \%)$ & $0.482^{B}$ & \\
\hline & II & $181(38.3 \%)$ & $11(55.0 \%)$ & & \\
\hline & III & $22(4.7 \%)$ & $1(5.0 \%)$ & & \\
\hline & IV & $4(0.8 \%)$ & $0(0.0 \%)$ & & \\
\hline \multirow[t]{3}{*}{ Smoking } & Current & $243(52.6 \%)$ & $7(46.7 \%)$ & $0.896^{\mathrm{B}}$ & $1.019(0.373-2.786)$ \\
\hline & Previous & $51(11.0 \%)$ & $2(13.3 \%)$ & & $1.316(0.257-6.751)$ \\
\hline & Never & $168(36.4 \%)$ & $6(40.0 \%)$ & & \\
\hline \multicolumn{2}{|c|}{ Comorbidities } & $218(42.3 \%)$ & $10(50.0 \%)$ & $1.000^{\mathrm{A}}$ & \\
\hline & Diabetes Mellitus & $24(4.7 \%)$ & $1(5.0 \%)$ & & \\
\hline \multicolumn{2}{|c|}{ Medication use } & $126(25.2 \%)$ & $6(30.0 \%)$ & $0.606^{A}$ & \\
\hline \multicolumn{2}{|c|}{ Trauma mechanism } & & & $0.185^{\mathrm{A}}$ & \\
\hline & LET & $216(36.8 \%)$ & $5(21.7 \%)$ & & \\
\hline & HET & $371(63.2 \%)$ & $18(78.3 \%)$ & & \\
\hline \multicolumn{2}{|c|}{ Time trauma to ED } & $0.0(0.0-0.0)$ & $0(0-0)$ & 0.477 & \\
\hline \multicolumn{2}{|c|}{ Gardner's angle } & $18.0(7.0-30.0)$ & $12.0(2.5-23.0)$ & 0.332 & \\
\hline \multicolumn{2}{|c|}{ Böhler's angle } & $8.0(-5.0-18.0)$ & $\begin{array}{c}9.0(-25.0- \\
20.0)\end{array}$ & 0.580 & \\
\hline \multicolumn{2}{|l|}{ Side } & & & $0.733^{A}$ & \\
\hline & Unilateral & $471(87.2 \%)$ & 17 (85.0\%) & & \\
\hline & Bilateral & $69(12.8 \%)$ & $3(15.0 \%)$ & & \\
\hline \multicolumn{2}{|c|}{ Fracture (Open/Closed) } & & & $0.000^{A}$ & \\
\hline & Open & 25 (4.1\%) & $12(50.0 \%)$ & & \\
\hline & Closed & $583(95.9 \%)$ & $12(50.0 \%)$ & & \\
\hline \multicolumn{2}{|c|}{ Fracture type } & & & $0.006^{A}$ & $3.043(1.063-8.714)$ \\
\hline & Non-tongue-type & $331(54.4 \%)$ & $6(25.0 \%)$ & & \\
\hline & Tongue-type & $277(45.6 \%)$ & $18(75.0 \%)$ & & \\
\hline \multicolumn{2}{|c|}{ Soft tissue compromise } & $162(26.6 \%)$ & $16(66.7 \%)$ & $0.000^{A}$ & \\
\hline & Posterior & 59 (9.7\%) & $4(16.7 \%)$ & $0.286^{A}$ & \\
\hline \multicolumn{2}{|c|}{ Additional injury } & $228(42.4 \%)$ & $11(55.0 \%)$ & $0.358^{\mathrm{A}}$ & \\
\hline \multicolumn{2}{|c|}{ Surgery } & $510(83.9 \%)$ & $22(91.7 \%)$ & $0.403^{\mathrm{A}}$ & $1.197(0.265-5.399)$ \\
\hline \multicolumn{2}{|c|}{ Time trauma to surgery } & $10.5(6.0-16.0)$ & $5.0(0.0-17.0)$ & 0.022 & \\
\hline \multicolumn{2}{|c|}{ Delay to surgery } & & & $0.002^{\mathrm{B}}$ & \\
\hline \multicolumn{2}{|c|}{$0-2$ days } & $56(11.2 \%)$ & $8(36.4 \%)$ & & \\
\hline \multicolumn{2}{|l|}{ 3-7 days } & $112(22.4 \%)$ & $4(18.2 \%)$ & & \\
\hline \multicolumn{2}{|c|}{ 8-14 days } & $170(33.9 \%)$ & $2(9.1 \%)$ & & \\
\hline \multicolumn{2}{|c|}{ >15 days } & $163(32.5 \%)$ & $8(36.4 \%)$ & & \\
\hline Hospital & of stay & $7.0(5.0-15.0)$ & $15.0(7.0-54.8)$ & 0.002 & $1.020(1.002-1.037)$ \\
\hline Complica & & $350(57.6 \%)$ & $24(100.0 \%)$ & $0.000^{A}$ & \\
\hline & Infection & $121(19.9 \%)$ & $16(66.7 \%)$ & $0.000^{A}$ & \\
\hline & Sup. infection & $69(11.3 \%)$ & $8(33.3 \%)$ & $0.005^{A}$ & \\
\hline & Deep infection & $73(12.0 \%)$ & $15(62.5 \%)$ & $0.000^{A}$ & \\
\hline & Necrosis & $28(4.6 \%)$ & $12(50.0 \%)$ & $0.000^{\mathrm{A}}$ & \\
\hline
\end{tabular}

Univariate OR (95\% Cl) for tongue-type fractures: 3.585 (95\% Cl 1.404-9.155, $\mathbf{p}=\mathbf{0 . 0 0 8 )}$.

A, Fisher's Exact Test; ${ }^{\circ}$, Pearson Chi-Square test 
Table 10: Covariates for the study population with versus without partial thickness lesion

\begin{tabular}{|c|c|c|c|c|c|}
\hline \multicolumn{2}{|l|}{ Variable } & $\begin{array}{c}\text { No Partial } \\
\text { thickness lesion }\end{array}$ & $\begin{array}{c}\text { Partial thickness } \\
\text { lesion }\end{array}$ & P-value & OR $(95 \% \mathrm{Cl})$ adjusted \\
\hline \multicolumn{2}{|c|}{ Gender (Male) } & $391(75.3 \%)$ & $33(80.5 \%)$ & $0.572^{\mathrm{A}}$ & \\
\hline \multicolumn{2}{|c|}{ Age (years) } & $44(34-56)$ & $43(34-57)$ & 0.850 & \\
\hline \multicolumn{2}{|c|}{$\mathrm{BMI}$} & $24(21-27)$ & $25.1(22.6-27.2)$ & 0.439 & \\
\hline \multirow[t]{4}{*}{ ASA } & 1 & $255(56.2 \%)$ & $19(48.7 \%)$ & $0.529^{A}$ & \\
\hline & II & $175(38.5 \%)$ & $17(43.6 \%)$ & & \\
\hline & III & $21(4.6 \%)$ & $2(5.1 \%)$ & & \\
\hline & IV & $3(0.7 \%)$ & $1(2.6 \%)$ & & \\
\hline \multirow[t]{3}{*}{ Smoking } & Current & $226(51.2 \%)$ & $24(66.7 \%)$ & $0.087^{B}$ & $1.822(0.790-4.205)$ \\
\hline & Previous & $48(10.9 \%)$ & $5(13.9 \%)$ & & $1.041(0.211-5.143)$ \\
\hline & Never & $167(37.9 \%)$ & $7(19.4 \%)$ & & \\
\hline \multicolumn{2}{|c|}{ Comorbidities } & $207(41.8 \%)$ & $21(52.5 \%)$ & $0.244^{\mathrm{A}}$ & \\
\hline & Diabetes Mellitus & $25(5.1 \%)$ & $0(0.0 \%)$ & $0.244^{\mathrm{A}}$ & \\
\hline \multicolumn{2}{|c|}{ Medication use } & $118(24.5 \%)$ & $14(35.9 \%)$ & $0.127^{A}$ & \\
\hline \multicolumn{2}{|c|}{ Trauma mechanism } & & & $0.049^{A}$ & $0.666(0.260-1.705)$ \\
\hline & LET & 209 (37.3\%) & $12(24.5 \%)$ & & \\
\hline & HET & $352(62.7 \%)$ & $37(75.5 \%)$ & & \\
\hline \multicolumn{2}{|c|}{ Time trauma to ED } & $0.0(0.0-0.0)$ & $0.0(0.0-0.0)$ & 0.096 & $0.552(0.131-2.327)$ \\
\hline \multicolumn{2}{|c|}{ Gardner's angle } & $16.0(6.5-29.0)$ & $28.5(21.3-40.0)$ & 0.009 & \\
\hline \multicolumn{2}{|c|}{ Böhler's angle } & $8.5(-4-18.0)$ & $-5.0(-18.0-11.0)$ & 0.001 & 0.983 (0.964-1.002) \\
\hline \multicolumn{2}{|c|}{ Side } & & & $0.029^{A}$ & $1.269(0.534-3.016)$ \\
\hline & Unilateral & 457 (88.1\%) & $31(75.6 \%)$ & & \\
\hline & Bilateral & $62(11.9 \%)$ & $10(24.4 \%)$ & & \\
\hline \multicolumn{2}{|c|}{ Fracture (Open/Closed) } & & & $0.018^{A}$ & \\
\hline & Open & $30(5.1 \%)$ & $7(14.3 \%)$ & & \\
\hline & Closed & $553(94.9 \%)$ & $42(85.7 \%)$ & & \\
\hline \multicolumn{2}{|c|}{ Fracture type } & & & $0.553^{\mathrm{A}}$ & $0.702(0.329-1.498)$ \\
\hline & Non-tongue-type & $313(53.7 \%)$ & $24(49.0 \%)$ & & \\
\hline & Tongue-type & $270(46.3 \%)$ & $25(51.0 \%)$ & & \\
\hline \multicolumn{2}{|c|}{ Soft tissue compromise } & $158(27.1 \%)$ & $20(40.8 \%)$ & $0.047^{A}$ & \\
\hline & Posterior & 59 (10.1\%) & $4(8.2 \%)$ & $0.807^{\mathrm{A}}$ & \\
\hline \multicolumn{2}{|c|}{ Additional injury } & $215(41.6 \%)$ & $24(58.5 \%)$ & $0.048^{\mathrm{A}}$ & 1.618 (0.664-3.944) \\
\hline \multicolumn{2}{|c|}{ Surgery } & $488(83.7 \%)$ & $44(89.8 \%)$ & $0.313^{\mathrm{A}}$ & $1.605(0.449-5.741)$ \\
\hline \multicolumn{2}{|c|}{ Time trauma to surgery } & $10.0(6.0-16.0)$ & $13.0(5.8-18.0)$ & 0.336 & \\
\hline \multicolumn{2}{|c|}{ Delay to surgery } & & & $0.149^{A}$ & \\
\hline \multicolumn{2}{|c|}{$0-2$ days } & 57 (11.9\%) & $7(16.3 \%)$ & & \\
\hline \multicolumn{2}{|c|}{ 3-7 days } & $112(23.3 \%)$ & $4(9.3 \%)$ & & \\
\hline \multicolumn{2}{|c|}{ 8-14 days } & $158(32.9 \%)$ & $14(32.6 \%)$ & & \\
\hline \multicolumn{2}{|c|}{ >15 days } & 153 (31.9\%) & $18(41.9 \%)$ & & \\
\hline Hospital & of stay & $7.0(5.0-15.0)$ & $13.0(8.0-31.0)$ & 0.001 & $1.022(1.004-1.040)$ \\
\hline Complice & & $325(55.7 \%)$ & $49(100.0 \%)$ & $0.000^{\mathrm{A}}$ & \\
\hline & Infection & $115(19.7 \%)$ & $22(44.9 \%)$ & $0.000^{\mathrm{A}}$ & \\
\hline & Sup. infection & $68(11.7 \%)$ & $9(18.4 \%)$ & $0.173^{\mathrm{A}}$ & \\
\hline & Deep infection & 70 (12.0\%) & $18(36.7 \%)$ & $0.000^{A}$ & \\
\hline & Necrosis & $27(4.6 \%)$ & $13(26.5 \%)$ & $0.000^{\mathrm{A}}$ & \\
\hline
\end{tabular}

Univariate OR $(95 \% \mathrm{Cl})$ for tongue-type fractures: $1.208(95 \% \mathrm{Cl} 0.674-2.164, \mathrm{p}=0.526)$

A, Fisher's Exact Test; ${ }^{\text {, }}$ Pearson Chi-Square test 
Table 11: Covariates for the study population with versus without necrosis

\begin{tabular}{|c|c|c|c|c|c|}
\hline \multicolumn{2}{|l|}{ Variable } & No Necrosis & Necrosis & P-value & OR (95\% Cl) adjusted \\
\hline \multicolumn{2}{|c|}{ Gender (Male) } & 395 (75.4\%) & $29(80.6 \%)$ & $0.553^{\mathrm{A}}$ & \\
\hline \multicolumn{2}{|c|}{ Age (years) } & $44(33-56)$ & $46(37-58)$ & 0.463 & \\
\hline \multicolumn{2}{|c|}{ BMI } & $24(21-27)$ & $25(20-28)$ & 0.851 & \\
\hline \multirow[t]{4}{*}{ ASA } & 1 & $258(56.2 \%)$ & $16(47.1 \%)$ & $0.147^{B}$ & \\
\hline & II & 175 (38.1\%) & $17(50.0 \%)$ & & 1.303 (0.613-2.768) \\
\hline & III & $23(5.0 \%)$ & $0(0.0 \%)$ & & N.D. \\
\hline & IV & $3(0.7 \%)$ & $1(2.9 \%)$ & & \\
\hline \multirow[t]{3}{*}{ Smoking } & Current & $235(52.7 \%)$ & $15(48.4 \%)$ & $0.650^{B}$ & $1.766(0.625-4.984)$ \\
\hline & Previous & $48(10.8 \%)$ & $5(16.1 \%)$ & & 0.795 (0.344-1.837) \\
\hline & Never & $163(36.3 \%)$ & $11(35.5 \%)$ & & \\
\hline \multicolumn{2}{|c|}{ Comorbidities } & $216(42.9 \%)$ & $12(37.5 \%)$ & $0.585^{A}$ & \\
\hline & Diabetes Mellitus & $24(4.8 \%)$ & $1(3.1 \%)$ & $1.000^{\mathrm{A}}$ & \\
\hline \multicolumn{2}{|c|}{ Medication use } & $124(25.4 \%)$ & $8(25.0 \%)$ & $1.000^{\mathrm{A}}$ & \\
\hline \multicolumn{2}{|c|}{ Trauma mechanism } & & & $1.000^{\mathrm{A}}$ & \\
\hline & LET & 207 (36.3\%) & $14(35.9 \%)$ & & \\
\hline & HET & $364(63.7 \%)$ & $26(64.1 \%)$ & & \\
\hline \multicolumn{2}{|c|}{ Time trauma to ED } & $0.0(0.0-0.0)$ & $0.0(0.0-0.0)$ & 0.371 & \\
\hline \multicolumn{2}{|c|}{ Gardner's angle } & $17.0(7.0-29.0)$ & $19.0(5.0-34.3)$ & 0.756 & \\
\hline \multicolumn{2}{|c|}{ Böhler's angle } & $8.0(-5-17.8)$ & $9.0(-10.0-20.0)$ & 0.962 & \\
\hline \multicolumn{2}{|c|}{ Side } & & & $0.798^{\mathrm{A}}$ & \\
\hline & Unilateral & $457(87.2 \%)$ & 31 (86.1\%) & & \\
\hline & Bilateral & $67(12.8 \%)$ & $5(13.9 \%)$ & & \\
\hline \multicolumn{2}{|c|}{ Fracture (Open/Closed) } & & & $0.000^{\mathrm{A}}$ & $2.693(0.874-8.302)$ \\
\hline & Open & $27(4.6 \%)$ & $10(25.0 \%)$ & & \\
\hline & Closed & $565(95.4 \%)$ & $30(75.0 \%)$ & & \\
\hline \multicolumn{2}{|c|}{ Fracture type } & & & $0.101^{A}$ & $1.244(0.590-2.621)$ \\
\hline & Non-tongue-type & 321 (54.2\%) & $16(40.0 \%)$ & & \\
\hline & Tongue-type & $271(45.8 \%)$ & $24(60.0 \%)$ & & \\
\hline \multicolumn{2}{|c|}{ Soft tissue compromise } & $156(26.4 \%)$ & $22(55.0 \%)$ & $0.000^{A}$ & 3.174 (1.411-6.995) \\
\hline & Posterior & $55(9.3 \%)$ & $8(20.0 \%)$ & $0.049^{A}$ & \\
\hline \multicolumn{2}{|c|}{ Additional injury } & $222(42.5 \%)$ & $19(52.8 \%)$ & $0.605^{\mathrm{A}}$ & \\
\hline \multicolumn{2}{|c|}{ Surgery } & $498(84.1 \%)$ & $34(85.0 \%)$ & $1.000^{\mathrm{A}}$ & $0.545(0.183-1.623)$ \\
\hline \multicolumn{2}{|c|}{ Time trauma to surgery } & $10.0(6.0-16.0)$ & $9.0(2.8-18.0)$ & 0.362 & \\
\hline \multicolumn{2}{|c|}{ Delay to surgery } & & & $0.223^{B}$ & \\
\hline \multicolumn{2}{|c|}{$0-2$ days } & $57(11.6 \%)$ & $7(21.2 \%)$ & & \\
\hline \multicolumn{2}{|l|}{ 3-7 days } & $111(22.7 \%)$ & $5(15.2 \%)$ & & \\
\hline \multicolumn{2}{|c|}{ 8-14 days } & $164(33.5 \%)$ & $8(24.2 \%)$ & & \\
\hline$>15$ days & & $158(32.2 \%)$ & $13(39.4 \%)$ & & \\
\hline Hospital & of stay & $7.0(5.0-15.0)$ & $12.0(6.0-21.0)$ & 0.041 & 1.010 (0.991-1.029) \\
\hline Complica & & $334(56.4 \%)$ & $40(100.0 \%)$ & $0.000^{\mathrm{A}}$ & \\
\hline & Infection & $116(19.6 \%)$ & $21(52.5 \%)$ & $0.000^{A}$ & \\
\hline & Sup. infection & $66(11.1 \%)$ & $11(27.5 \%)$ & $0.005^{A}$ & \\
\hline & Deep infection & $59(11.7 \%)$ & $19(47.5 \%)$ & $0.000^{A}$ & \\
\hline & Partial thickness & $36(6.1 \%)$ & $13(32.5 \%)$ & $0.000^{A}$ & \\
\hline & Full thickness & $12(2.0 \%)$ & $12(30.0 \%)$ & $0.000^{\mathrm{A}}$ & \\
\hline
\end{tabular}

Univariate OR $(95 \% \mathrm{Cl})$ for tongue-type fractures: $1.777(95 \% \mathrm{Cl}$ 0.925-3.413, $\mathrm{p}=0.084)$

A, Fisher's Exact Test; B, Pearson Chi-Square test 
Table 12: Covariates for the study population with versus without non-union

\begin{tabular}{|c|c|c|c|c|c|}
\hline \multicolumn{2}{|l|}{ Variable } & No Non-union & Non-union & P-value & OR (95\% Cl) adjusted \\
\hline \multicolumn{2}{|c|}{ Gender (Male) } & $130(24.3 \%)$ & $6(25.0 \%)$ & $1.000^{\mathrm{A}}$ & \\
\hline \multicolumn{2}{|c|}{ Age (years) } & $44(34-56)$ & $48(35-57)$ & 0.716 & \\
\hline \multicolumn{2}{|c|}{$\mathrm{BMI}$} & $\begin{array}{c}24.2(21.5- \\
27.2)\end{array}$ & $25.4(23.0-30.8)$ & 0.034 & $1.191(1.077-1.317)$ \\
\hline \multirow[t]{4}{*}{ ASA } & I & $265(56.3 \%)$ & $9(40.9 \%)$ & $0.208^{A}$ & \\
\hline & II & $179(38.0 \%)$ & 13 (59.1\%) & & \\
\hline & III & 23 (4.9\%) & $0(0.0 \%)$ & & \\
\hline & IV & $4(0.8 \%)$ & $0(0.0 \%)$ & & \\
\hline \multirow[t]{3}{*}{ Smoking } & Current & $241(52.9 \%)$ & $9(52.9 \%)$ & $0.554^{\mathrm{B}}$ & $0.201(0.019-2.174)$ \\
\hline & Previous & $51(11.2 \%)$ & $2(9.5 \%)$ & & $1.162(0.439-3.072)$ \\
\hline & Never & $164(36.0 \%)$ & $10(47.6 \%)$ & & \\
\hline \multicolumn{2}{|c|}{ Comorbidities } & $215(42.0 \%)$ & 13 (56.5\%) & $0.198^{\mathrm{A}}$ & \\
\hline & Diabetes Mellitus & $25(4.9 \%)$ & $0(0.0 \%)$ & $0.617^{A}$ & \\
\hline \multicolumn{2}{|c|}{ Medication use } & $124(24.9 \%)$ & $8(34.8 \%)$ & $0.327^{A}$ & \\
\hline \multicolumn{2}{|c|}{ Trauma mechanism } & & & $0.064^{\mathrm{A}}$ & $1.365(0.440-4.235)$ \\
\hline & LET & $216(37.0 \%)$ & $5(18.5 \%)$ & & \\
\hline & HET & $367(63.0 \%)$ & $22(81.5 \%)$ & & \\
\hline \multicolumn{2}{|c|}{ Time trauma to ED } & $0.0(0.0-0.0)$ & $0.0(0.0-0.0)$ & 0.372 & \\
\hline \multicolumn{2}{|c|}{ Gardner's angle } & $17.0(7.0-29.8)$ & $22.0(4.5-38.0)$ & 0.490 & \\
\hline \multicolumn{2}{|c|}{ Böhler's angle } & $8.0(-5.0-18.0)$ & $2.0(-20.0-13.0)$ & 0.042 & $0.980(0.956-1.004)$ \\
\hline \multicolumn{2}{|c|}{ Side } & & & $0.534^{A}$ & \\
\hline & Unilateral & $468(87.3 \%)$ & $20(83.3 \%)$ & & \\
\hline & Bilateral & $68(12.7 \%)$ & $4(16.7 \%)$ & & \\
\hline \multicolumn{2}{|c|}{ Fracture (Open/Closed) } & & & $0.005^{A}$ & $2.489(0.540-11.473)$ \\
\hline & Open & $31(5.1 \%)$ & $6(20.7 \%)$ & & \\
\hline & Closed & $572(94.9 \%)$ & $23(79.3 \%)$ & & \\
\hline \multicolumn{2}{|c|}{ Fracture type } & & & $0.704^{\mathrm{A}}$ & $1.172(0.454-3.024)$ \\
\hline & Non-tongue-type & $323(53.6 \%)$ & $14(48.3 \%)$ & & \\
\hline & Tongue-type & $280(46.4 \%)$ & 15 (51.7\%) & & \\
\hline \multicolumn{2}{|c|}{ Soft tissue compromise } & $166(27.5 \%)$ & $12(41.4 \%)$ & $0.137^{A}$ & $2.127(0.759-5.962)$ \\
\hline & Posterior & $60(10.0 \%)$ & $3(10.3 \%)$ & $1.000^{\mathrm{A}}$ & \\
\hline \multicolumn{2}{|c|}{ Additional injury } & $226(42.2 \%)$ & 13 (56.5\%) & $0.200^{A}$ & \\
\hline \multicolumn{2}{|c|}{ Surgery } & $512(84.9 \%)$ & $20(69.0 \%)$ & $0.033^{A}$ & $0.158(0.053-0.472)$ \\
\hline \multicolumn{2}{|c|}{ Time trauma to surgery } & $10.0(6.0-16.0)$ & $6.5(0.8-14.3)$ & 0.070 & \\
\hline \multicolumn{2}{|c|}{ Delay to surgery } & & & $0.016^{\mathrm{B}}$ & \\
\hline \multicolumn{2}{|c|}{$0-2$ days } & 57 (11.3\%) & $7(35.0 \%)$ & & \\
\hline \multicolumn{2}{|l|}{ 3-7 days } & $113(22.5 \%)$ & $3(15.0 \%)$ & & \\
\hline \multicolumn{2}{|c|}{ 8-14 days } & $168(33.4 \%)$ & $4(20.0 \%)$ & & \\
\hline$>15$ days & & $165(32.8 \%)$ & $6(30.0 \%)$ & & \\
\hline Hospital & of stay & $7.0(5.0-15.0)$ & $9.0(6.0-34.0)$ & 0.081 & 1.017 (0.997-1.038) \\
\hline Complice & & $345(57.2 \%)$ & $29(100.0 \%)$ & $0.000^{A}$ & \\
\hline & Infection & $124(20.6 \%)$ & $13(44.8 \%)$ & $0.004^{\mathrm{A}}$ & \\
\hline & Sup. infection & 69 (11.4\%) & $8(27.6 \%)$ & $0.017^{A}$ & \\
\hline & Deep infection & 78 (12.9\%) & 10 (34.5\%) & $0.003^{A}$ & \\
\hline & Partial thickness & $45(7.5 \%)$ & $4(13.8 \%)$ & $0.271^{A}$ & \\
\hline & Full thickness & $22(3.6 \%)$ & $2(6.9 \%)$ & $0.303^{\mathrm{A}}$ & \\
\hline
\end{tabular}

Univariate OR $(95 \% \mathrm{Cl})$ for tongue-type fractures: $1.236(95 \% \mathrm{Cl} 0.586-2.605, \mathrm{p}=0.578)$

A, Fisher's Exact Test; ${ }^{\circ}$, Pearson Chi-Square test 


\section{REFERENCES}

1. Essex-Lopresti $P$. The mechanism, reduction technique, and results in fractures of the os calcis. Br J Surg. 1952;39(157):395-419.

2. Gardner MJ, Nork SE, Barei DP, Kramer PA, Sangeorzan BJ, Benirschke SK. Secondary soft tissue compromise in tongue-type calcaneus fractures. J Orthop Trauma. 2008;22(7):439-45.

3. De Boer AS, Van Lieshout EM, Den Hartog D, Weerts B, Verhofstad MH, Schepers T. Functional outcome and patient satisfaction after displaced intra-articular calcaneal fractures: a comparison among open, percutaneous, and nonoperative treatment. $\mathrm{J}$ Foot Ankle Surg. 2015;54(3):298-305.

4. Gitajn IL, Abousayed M, Toussaint RJ, Vrahas M, Kwon JY. Calcaneal avulsion fractures: a case series of 33 patients describing prognostic factors and outcomes. Foot Ankle Spec. 2015;8(1):10-7.

5. Kwon JY, Guss D, Lin DE, Abousayed M, Jeng C, Kang S, et al. Effect of Delay to Definitive Surgical Fixation on Wound Complications in the Treatment of Closed, Intraarticular Calcaneus Fractures. Foot Ankle Int. 2015;36(5):508-17.

6. Fulkerson EW, Egol KA. Timing issues in fracture management: a review of current concepts. Bull NYU Hosp Jt Dis. 2009;67(1):58-67.

7. Chhabra N, Sherman SC, Szatkowski JP. Tongue-type calcaneus fractures: a threat to skin. Am J Emerg Med. 2013;31(7):1151 e3-4.

8. Sanders R, Fortin P, DiPasquale T, Walling A. Operative treatment in 120 displaced intraarticular calcaneal fractures. Results using a prognostic computed tomography scan classification. Clin Orthop Relat Res. 1993(290):87-95.

9. Gustilo RB, Anderson JT. Prevention of infection in the treatment of one thousand and twenty-five open fractures of long bones: retrospective and prospective analyses. J Bone Joint Surg Am. 1976;58(4):453-8.

10. Böhler L. Diagnosis, pathology and treatment of fractures of the os calcis. J Bone Joint Surg 1931;13: 75-89

11. Snoap T, Jaykel M, Williams C, Roberts J. Calcaneus Fractures: A Possible Musculoskeletal Emergency. J Emerg Med. 2016.

12. Ghorbanhoseini M, Ghaheri A, Walley KC, Kwon JY. Superior Tuber Displacement in Intraarticular Calcaneus Fractures. Foot Ankle Int. 2016;37(10):1076-83.

13. Watson TS. Soft tissue complications following calcaneal fractures. Foot Ankle Clin. 2007;12(1):107-23. 